\title{
Midday auroral breakup events and related energy and momentum transfer from the magnetosheath
}

Article

Published Version

Sandholt, P. E., Lockwood, M., Oguti, T., Cowley, S. W. H., Freeman, K. S. C., Lybekk, B., Egeland, A. and Willis, D. M. (1990) Midday auroral breakup events and related energy and momentum transfer from the magnetosheath. Journal of Geophysical Research, 95 (A2). pp. 1039-1060. ISSN 01480227 doi: https://doi.org/10.1029/JA095iA02p01039 Available at https://centaur.reading.ac.uk/38868/

It is advisable to refer to the publisher's version if you intend to cite from the work. See Guidance on citing.

Published version at: http://dx.doi.org/10.1029/JA095iA02p01039

To link to this article DOI: http://dx.doi.org/10.1029/JA095iA02p01039

Publisher: American Geophysical Union

All outputs in CentAUR are protected by Intellectual Property Rights law, including copyright law. Copyright and IPR is retained by the creators or other copyright holders. Terms and conditions for use of this material are defined in the End User Agreement. 


\section{CentAUR}

Central Archive at the University of Reading

Reading's research outputs online 
MIDDAY AURORAL BREAKUP EVENTS AND RELATED ENERGY AND MOMENTUM TRANSFER FROM THE MAGNETOSHEATH

\author{
P. E. Sandholt, 1 M. Lockwood,2 T. Oguti, ${ }^{3}$ S. W. H. Cowley,,$^{4}$. S. C. Freeman, ${ }^{2}$ \\ B. Lybekk, ${ }^{1}$. Egeland, 1 and D. M. Willis ${ }^{2}$
}

\begin{abstract}
Combined observations by meridian-scanning photometers, all-sky auroral TV camera and the EISCAT radar permitted a detailed analysis of the temporal and spatial development of the midday auroral breakup phenomenon and the related ionospheric ion flow pattern within the $71^{\circ}-75^{\circ}$ invariant latitude radar field of view. The radar data revealed dominating northward and westward ion drifts, of magnitudes close to the corresponding velocities of the discrete, transient auroral forms, during the two different events reported here, characterized by IMF $\left|\mathrm{BY}_{\mathrm{Y}} / \mathrm{B}_{2}\right|<1$ and $>2$, respectively (IMF $B_{2}$ between -8 and $-3 n T$ and $B y, 0)$. The spatial scales of the discrete optical events were $-50 \mathrm{~km}$ in latitude by - $500 \mathrm{~km}$ in longitude, and their lifetimes were less than $10 \mathrm{~min}$. Electric potential enhancements with peak values in the $30-50 \mathrm{kV}$ range are inferred along the discrete arc in the IMF $\left|B_{y} / B_{z}\right|$ $<1$ case from the optical data and across the latitudinal extent of the radar field of view in the $\left|B_{y} / B_{z}\right|$, 2 case. Joule heat dissipation rates in the maximum phase of the discrete structures of ${ }^{-100}$ ergs $\mathrm{cm}^{-2} \mathrm{~s}^{-1}\left(0.1 \mathrm{~W} \mathrm{\textrm {m } ^ { - 2 } )}\right.$ are estimated from the photometer intensities and the ion drift data. These observations combined with the additional characteristics of the events, documented here and in several recent studies (i.e., their quasi-periodic nature, their motion pattern relative to the persistent cusp or cleft auroral arc, the strong relationship with the interplanetary magnetic field and the associated ion drift/E field events and ground magnetic signatures), are considered to be strong evidence in favour of a transient, intermittent reconnection process at the dayside magnetopause and associated energy and momentum transfer to the ionosphere in the polar cusp and cleft re-
\end{abstract}

\footnotetext{
IDepartment of Physics, University of Oslo, Norway.

2 Rutherford Appleton Laboratory,

Chilton, United Kingdom.

${ }^{3}$ Geophysics Research Laboratory, Tokyo, Japan.

4 Blackett Laboratory, Imperial College, London.

Copyright 1990 by the

American Geophysical Union.

Paper number $89 \mathrm{JA} 00817$. 0148-0227/90/89JA-00817\$05.00
}

gions. The filamentary spatial structure and the spectral characteristics of the optical signature indicate associated localized - $1-\mathrm{kV}$ potential drops between the magnetopause and the ionosphere during the most intense auroral events. The duration of the events compares well with the predicted characteristic times of momentum transfer to the ionosphere associated with the flux transfer eventrelated current tubes. It is suggested that, after this 2-10 min interval, the sheath particles can no longer reach the ionosphere down the open flux tube, due to the subsequent super-Alfvenic flow along the magnetopause, conductivities are lower and much less momentum is extracted from the solar wind by the ionosphere. The recurrence time (3-15 min) and the local time distribution !" 0900-1500 MLT) of the dayside auroral breakup events, combined with the above information, indicate the important roles of transient magnetopause reconnection and the polar cusp and cleft regions in the transfer of momentum and energy between the solar wind and the magnetosphere.

\section{Introduction}

The progress of theoretical and experimental studies related to solar windmagnetosphere coupling at the dayside magnetopause during recent years has stimulated an increased interest in ground-based observations of the dayside, high-latitude ionosphere [e.g., Cowley, 1986]. One crucial question is to what extent the polar cusp and cleft regions contribute to the overall mass, momentum and energy transfer between the shocked solar wind (magnetosheath) and the ionosphere [e.g.. Baumjohann and Paschmann, 1987]. Furthermore, the basic physics of the energy/momentum transfer processes at the dayside magnetopause is a matter of great controversy at present [e.g., Lundin, 1987].

It is expected that ground-based remote sensing techniques, with their ability to continuously monitor the temporal and spatial variations of the ionospheric signatures, will have a great impact on this problem. Among the most relevant parameters to observe are the optical aurora, the ionospheric ion drift/E field and the associated magnetic field perturbations. Thus, simultaneous, coordinated observations of these parameters are expected to be a most important project in the coming years. 
Distinct responses to change in the solar wind electric field have been documented by observing these parameters separately or in combination [e.g., Rishbeth et al., 1985; Lockwood et al., 1986; Etemadi et al., 1988; Lockwood and Cow ley, 1989; Todd et al., 1988b; Sandholt et al.. 1985, 1986a,b; Clauer et al.. 1984; Friis-Christensen, 1986], indicating a direct relationship between the solar wind - magnetosphere interaction process at the magnetopause and the polar cusp/cleft ionosphere. A minimum ionospheric response time of a few minutes in the early post noon sector was reported by Etemadi et al. [1988], Todd et al. [1988b], and Lockwood and Cowley [1988]. In this study we focus on certain transient, intermittent ionospheric events near the dayside polar cap boundary and discuss the possible relationship with magnetopause flux transfer events and associated energy and momentum transfer to the cusp/cleft ionosphere, based on coordinated observations of the three parameters mentioned above.

The optical signatures and the related ground magnetic impulses, named midday auroral breakup events by sandholt et al. [1989a], have been reported in a series of papers [Sandholt et al., 1985; Oguti et al., 1988; Kokubun et al., 1988; Sandholt and Egeland, 1988; Sandholt, 1987, 1988; Sandholt et al., 1989a]. These transient events form on the equatorward edge of the background, stable cusp or cleft aurora, propagate poleward and fade within their lifetime of 2-10 min. They are observed as arcs or arc fragments in both $630-\mathrm{nm}$ and $557.7-\mathrm{nm}$ auroral emissions. Ion drift events related to the optical phenomenon have been reported by Lockwood et al. [1989b], Sandholt and Egeland [1988], and Sandholt et al. [1989b]. Some characteristics of these events are: (1) occurrence in the 0900-1500 MLT interval, (2) occurrence almost exclusively during interplanetary magnetic field (IMF) $\mathrm{B}_{2}<0$, (3) $2^{\circ}-5^{\circ}$ poleward motion (velocity $<1.5 \mathrm{~km} \mathrm{~s} \mathrm{~s}^{-1}$ ) of the discrete auroral structure across the persistent cusp or cleft aurora, after a localized breakup near the cusp/cleft equatorward boundary, (4) longitudinal motion (velocity $-2-5 \mathrm{~km} \mathrm{~s}^{-1}$ ) $\mathrm{re}-$ lated to IMF $B_{Y}$, i.e., westward or eastward corresponding to positive or negative $B_{Y}$, respectively, in the northern hemisphere, (5) latitudinal width of arcs of - 50-100 km, (6) longitudinal extent of arcs of - 500-1000 km, (7) lifetime 2-10 min, (8) quasi-periodic occurrence with recurrence time - 3-15 min, (9) enhanced westward ion drift/northward $E$ field (IMF $B y$, 0 , northern hemisphere), i.e., $V_{W}-2-5 \mathrm{~km} / \mathrm{s}$ or $E_{N}-100-300 \mathrm{mV} / \mathrm{m}$, (10) precipitating electron flux with average energies - $0.3-2 \mathrm{keV}$, and (11) 0 $200 \mathrm{nT} H$ component magnetic deflections in the form of single, monopolar or bipolar pulses. The deflection amplitude is determined by the ionospheric Hall conductance, electric field and latitudinal extent of the Hall current filament associated with the discrete auroral arc (from the Biot-savart law).

The events described above should be distinguished from another category of dayside impulsive events with similar spatial and temporal scales which have been reported in several recent studies [e.g., Friis-Christensen et al., 1988 , Glassmeier et al., 1989; Potemra et al., 1989; Sibeck et al., 1989a,b; McHenry et al., 1989]. Farrugia et al. [1989] show this second class of phenomena to be closely associated with solar wind dynamic pressure variations and consequent magnetopause motions. The typical inferred ionospheric signatures, i.e., a twin vortex convection pattern with related field-aligned current filaments separated by - $1000 \mathrm{~km}$ in the east-west direction [cf. Friis-Christensen et al., 1988], occur on closed field lines near the polar cap boundary, predominantly on the dayside, and are propagating tailward at speeds - $5 \mathrm{~km} / \mathrm{s}$. Poleward motions are not typical. In contrast to this, the dayside breakup events occur frequently at noon (within 0900-1500 MLT; with no midday gap), they are observed during intervals of extremely steady solar wind flow, the pattern of motion is strongly influenced by the IMF orientation, and they are invariably moving poleward (northwest, north or northeast, depending on IMF BY). Thus, when $B y$ is positive, northwestward motion is typical, also in the postnoon sector, i.e., sunward motions can occur in that case. These differences do not necessarily mean that the two phenomena are always unrelated, however [of., D. G. sibeck and J. T. Gosling, Solar wind dynamic pressure variations and possible ground signatures of flux transfer events, submitted to Journal of Geophysical Research, 1989].

Lockwood et al. [1989] found that the quasi-periodic auroral breakup events in the early postnoon sector were assuciated with bursts of enhanced ion flow, as observed at a similar longitude by EISCAT, and that the transient arcs and arc fragments marked the flow reversal boundary between westward (IMF $B_{Y}, 0$ ) flow to the south (collocated with the persistent cleft or cusp aurora) and eastward flow to the north. This was shown to be consistent with southwood's model of the flux transfer event (FTE)-related ionospheric flow pattern [Southwood, 1985;1987].

In this study, we examine the detailed temporal and spatial evolution of the auroral structures in relation to EISCAT ion drift observations, using all-sky TV data in combination with the photometer data. In addition, the associated geomagnetic signatures are obtained from a four-point meridian chain of magnetometer stations located in the invariant latitude range $67^{\circ}-76^{\circ}$. 
The four different data sets are presented in section 2. These observations are then discussed in section 3.1 , with emphasis on certain characteristic aspects of auroral electrodynamics in the cusp ionosphere. The relationships between the observed cusp auroral dynamics and localized, sporadic reconnection at the dayside magnetopause and magnetosphere-ionosphere coupling are elaborated in section 3.2 , and related to recently published models. The earlier search for ionospheric signatures of flux transfer events and the main findings of the present work are summarized in section 4 . The ground magnetic perturbations associated with one of the midday auroral breakup events discussed in the paper are calculated in the appendix, using the optical intensities in combination with the ion drift data.

\section{Observations}

Figure 1 shows the meridian scanned every $18 \mathrm{~s}$ by the photometers at Ny Alesund, spitzbergen [e.g., Sandholt et al., 1985 , 1986a], in relation to the two azimuths employed by the EISCAT program CP-4 (identical to the POLAR experiment described by van Eyken et al. [1984] and willis et al. [1986], except that lineof-sight velocities, vıos, are recorded

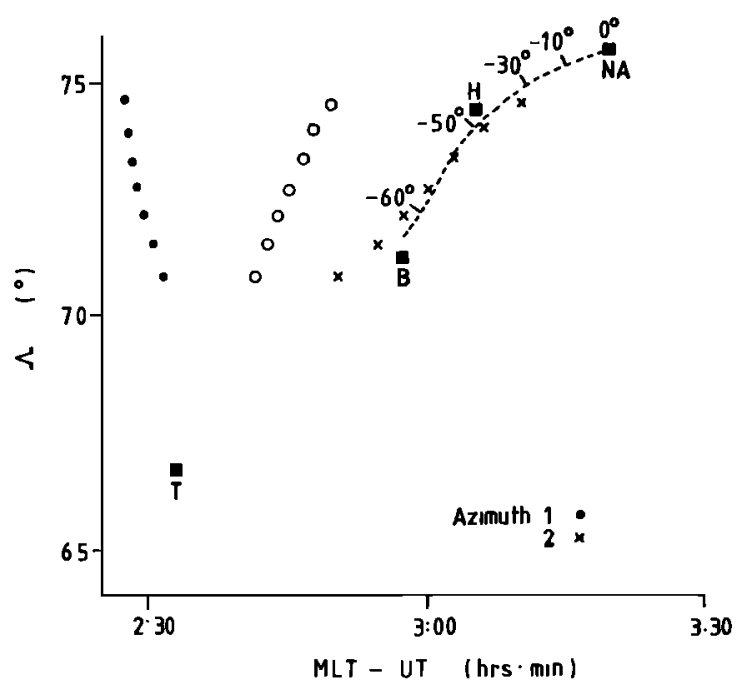

Fig. 1. The relative orientations of the southern half of the scan covered by the photometers at Ny Alesund (dashed line), and the two azimuths employed by the EISCAT CP-4 experiment. The open circles are the points for each range gate, midway between the two azimuths, to which the vector data are ascribed. Also shown are the locations of magnetometers at $\mathrm{Ny}$ Alesund (NA), Hornsund (H), Bjørnøya (B), and Troms $\emptyset(T)$. The locations of $630.0 \mathrm{~nm}$ emissions, for an assumed altitude of 250 $\mathrm{km}$, are shown for various zenith angles (positive northward) at Ny Alesund. every $10 \mathrm{~s})$. The positions marked on the photometer scan (dashed line) are for the given zenith angle at Ny Alesund (NA) (positive to the north), for an assumed $630-\mathrm{nm}$ emission altitude of $250 \mathrm{~km}$. The solid circles and crosses mark the centers of the radar scattering volumes for azimuths 1 and 2 , respectively $1332^{\circ}$ and $356^{\circ}$ east of geographic north at Troms $\varnothing$, T). Vectors derived from the beamswinging technique are ascribed to the points marked by open circles, midway between the azimuths on the same $L$ shell. Solid squares mark the location of magnetometers at Ny Alesund (NA), Hornsund $(H)$, Bjørnøya (B), and Troms $\varnothing$ (T). All positions and scans are mapped into an invariant latitude - MLT frame at 1000 UT on January 12 , 1988 . The radar beam swings between these two azimuths with a $5 \mathrm{~min}$ cycle. The joint radar-optical observations described here were made on JanuarY 12, 1988, between 0900 and 0930 UT. This period is at the start of a longer period (2.5 hours) during which nine dayside breakup events, with associated ion flow bursts, are observed [Lockwood et al., 1989]. In this study the multichannel meridian photometer data are combined with all-sky TV camera images, in order to map the two-dimensional auroral distribution with high temporal resolution for two of these events.

\subsection{Photometer and Radar Observations}

Figure 2 shows meridian photometer scans at $630.0-$ and $557.7-\mathrm{nm}$ wavelengths for the interval 0906-0930 UT (Figures 2a and $2 \mathrm{~b}$ ) and ion drift data (Figures $2 \mathrm{c}$ to 2i). This interval corresponds to roughly 1145-1215 MLT for the vector radar data and to about 1215-1245 MLT for the optical events between Hornsund and $\mathrm{NY} A l e-$ sund (Figure 1).

The photometer data for this 25-min period show a red-dominated, persistent cusp or cleft arc, together with two major transient optical events at 09090912 UT and 0920-0928 UT. A clear poleward motion of the two transient structures is observed. Assuming a red line emission peak altitude of $250 \mathrm{~km}$, northward velocities of 1.2 and $0.7 \mathrm{~km} \mathrm{~s} \mathrm{~s}^{-1}$ are derived for the intervals 0909:33-0911:43 and 0921:35-0924:10 UT, respectively. The green line emission is strongly and transiently enhanced during these intervals, with a peak intensity $-15 \mathrm{kR}$ at $0922 \mathrm{UT}$. Before and after the transient events the green line intensities observed within the persistent arc are generally less than $1 \mathrm{kR}$. This low background is typical for a limited region around local noon, characterized by a minimum of discrete auroral forms, often referred to as the midday gap [e.g., Cogger et al., 1977]; note, however, that there is no gap in the occurrence of discrete transient arcs, of the kind shown in Figure 2 [cf. also Sandholt et al., 1989a]. 
(a)

(b)

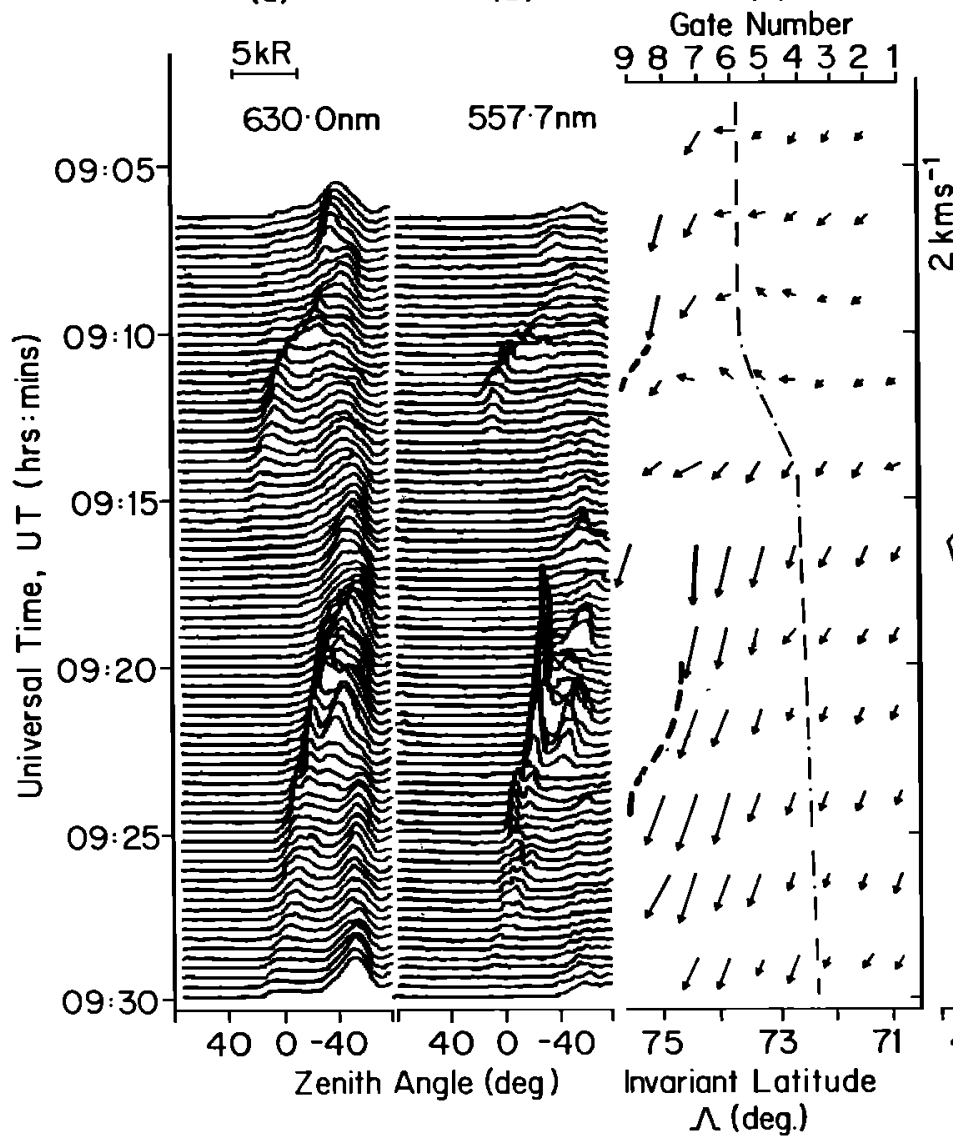

(d)

(e)

(f)

(g)

(h)

(i)

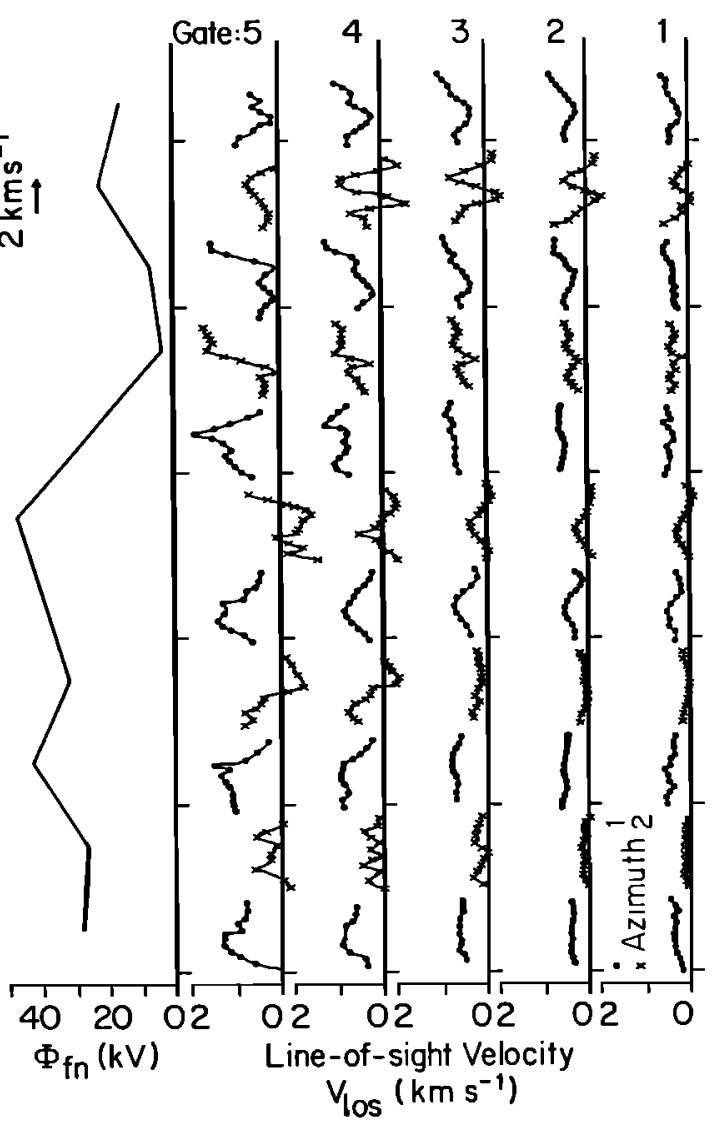

Fig. 2. Photometer and EISCAT observations on January 12, 1988. The panels show the intensity of (a) 630.0-nm and (b) 557.7-nm emissions as a function of zenith angle (zero corresponding to overhead at Ny Alesund) and universal time. (c) The observed ionospheric flow vectors, (d) the potential, if n, observed across the north-south extent of the EISCAT field of view, and (e)-(i) the 10-s line-of-sight velocities (positive away from radarl observed in gates 1-5; circles being for azimuth 1 , crosses for azimuth 2. The locations of the equatorward boundary of the persistent cusplike emission, as well as the transient arcs at 0909-0912 and 0920-0927 UT, are marked in Figure 2c. These estimates are obtained from the optical data, assuming emission altitudes of 250 and $130 \mathrm{~km}$ (lower border) for the red and the green lines, respectively.

In Figure 2c, 2.5-min resolution vectors derived in the way described by Willis et al. [1986] are shown for the first 7-9 gates (for which the signal-tonoise ratio was sufficient). The latitude of the equatorward boundary of the persistent red-dominated cleft/cusp aurora is marked in this panel by the dot-and dash line. In addition, the dashed lines give the locations of the transient optical structures as a function of time, determined by the photometer traces and the TV images shown in Figure 3. The events of enhanced westward ion drift are seen to be in a band of latitudes collocated with the cusp like emission. The vectors show a rotation of flow toward north for the northernmost gates $(7$ and 8) in the 0909-0912 UT period, when the optical arc was intensifying and moving poleward, followed by a swing to enhanced westward flow preceding the onset of the second optical event at 0920 UT.

Care must be taken when interpreting the vector data because flow changes are taking place over time scales comparable with the radar beam-swinging period. Etemadi et al. [1989] have considered the effects of the use of this technique with step function changes in real flow speed, and note two effects. "Smoothing" causes the observed flow increase to be spread over a 5-min period about the change. while "mixing" causes a spurious northward component to be introduced by real changes in westward flow (and vice versa). If the flow is purely westward, only the smoothing effect needs to be considered because the effect of "mixing" on the northward flow component is very small for the CP-4 beam geometry. The nature of the spurious "mixing" effects 


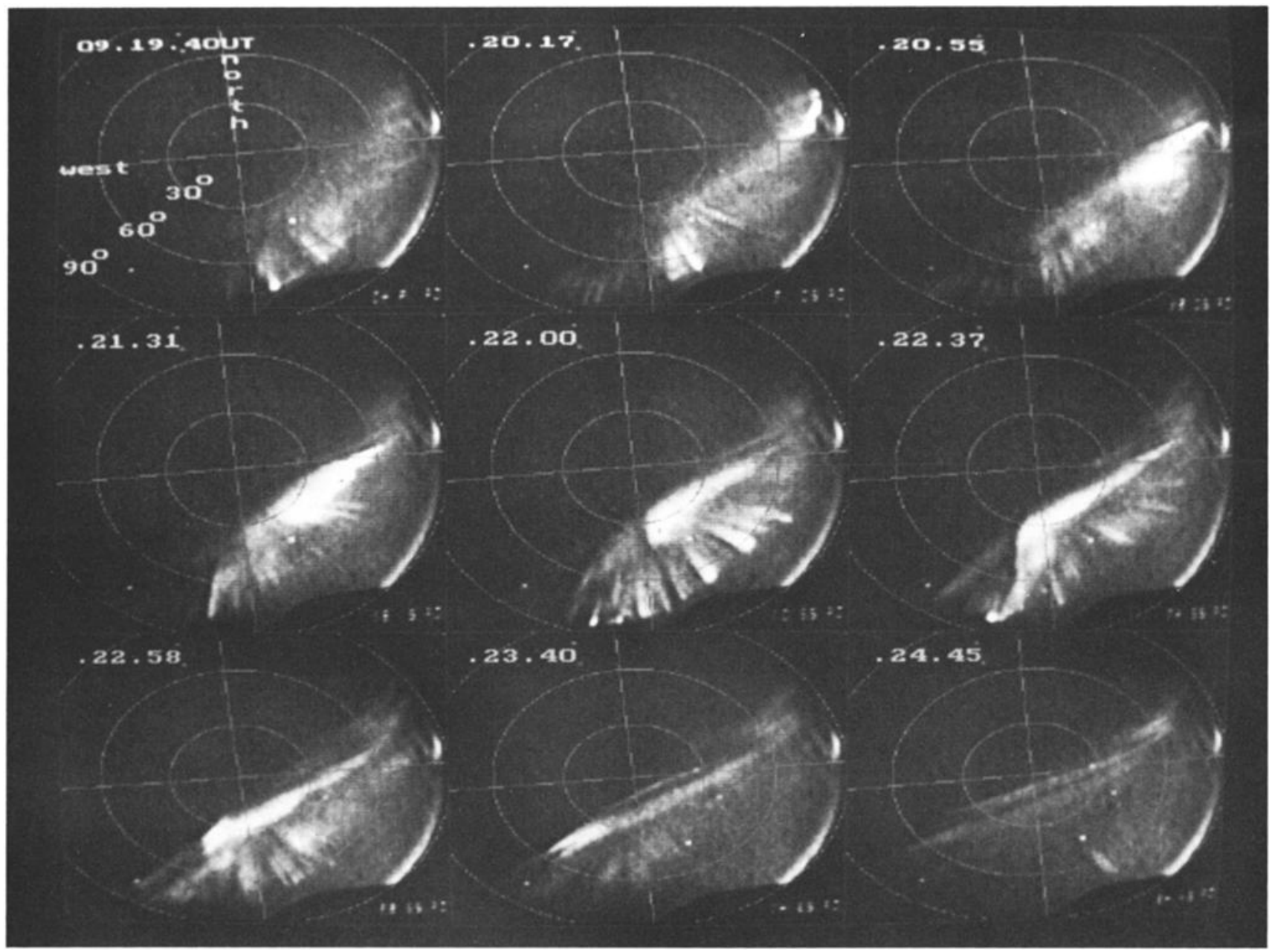

Fig. 3a. A11-sky picture sequence of discrete auroral forms within 0919:40-0924:45 UT in zenith angle-geographical azimuth coordinates.

depends on the phase of the flow onset relative to the beam-swinging cycle, and hence we would expect different effects for each event if "mixing" was a major factor. The lack of such variety in Figure 3 of Lockwood et al. [1989] confirms that "smoothing" is the dominant effect. In practice, we may regard the data as three-point running means of $2.5-$ min resolution observations.

For each set of vectors at a given UT, the potential of across the north-south dimension of the radar field of view is computed by integrating the observed northward electric field over the first seven radar gates. Figure $2 d$ shows the variation of $\Phi_{f} n$, which, like the vectors from which it is derived, is smoothed over a 7.5-min period. Figures $2 \mathrm{e}$ to $2 i$ of Figure 2 show the 10-s resolution line-of-sight velocities observed along the two azimuths by the EISCAT radar (circles are for azimuth 1 and crosses for azimuth 2) in gates 1-5 (cf. Figure 1).

The line-of-sight velocities, vlos, observed by the radar show that the onset of the first event is marked by two cycles of pulsations of period $\sim 80 \mathrm{~s}$. These observations are to the south of both the transient optical feature and the channel of flow, which is enhanced during the event onset (see the vector data, Figure 2c). Gates 1-5 are presented because only they had sufficient signalto-noise ratio to give reliable vios values (see analysis of errors by Bromage [1984]). Such pulsations are also present, although less clearly defined, after 0915 UT, at the onset of the second event. The vios indicate that the largest northward flows in the first event may decay rapidly (0907:30-0910:00 UT at azimuth 1 and 0910:00-0912:30 at azimuth 2). The onset of enhanced westward flow in the second event is difficult to detect because of the superposed pulsations. However, the rise in vios for azimuth 1 commencing near 0912:30 and the decrease for azimuth 2 commencing near 0915:00 could both be interpreted as such an onset. For gate 5, the two azimuths are $315 \mathrm{~km}$ apart, and hence we would, with this interpretation of the vios data, predict a westward propagation of the flow onset of $2 \mathrm{~km} \mathrm{~s}^{-1}$. This is close 


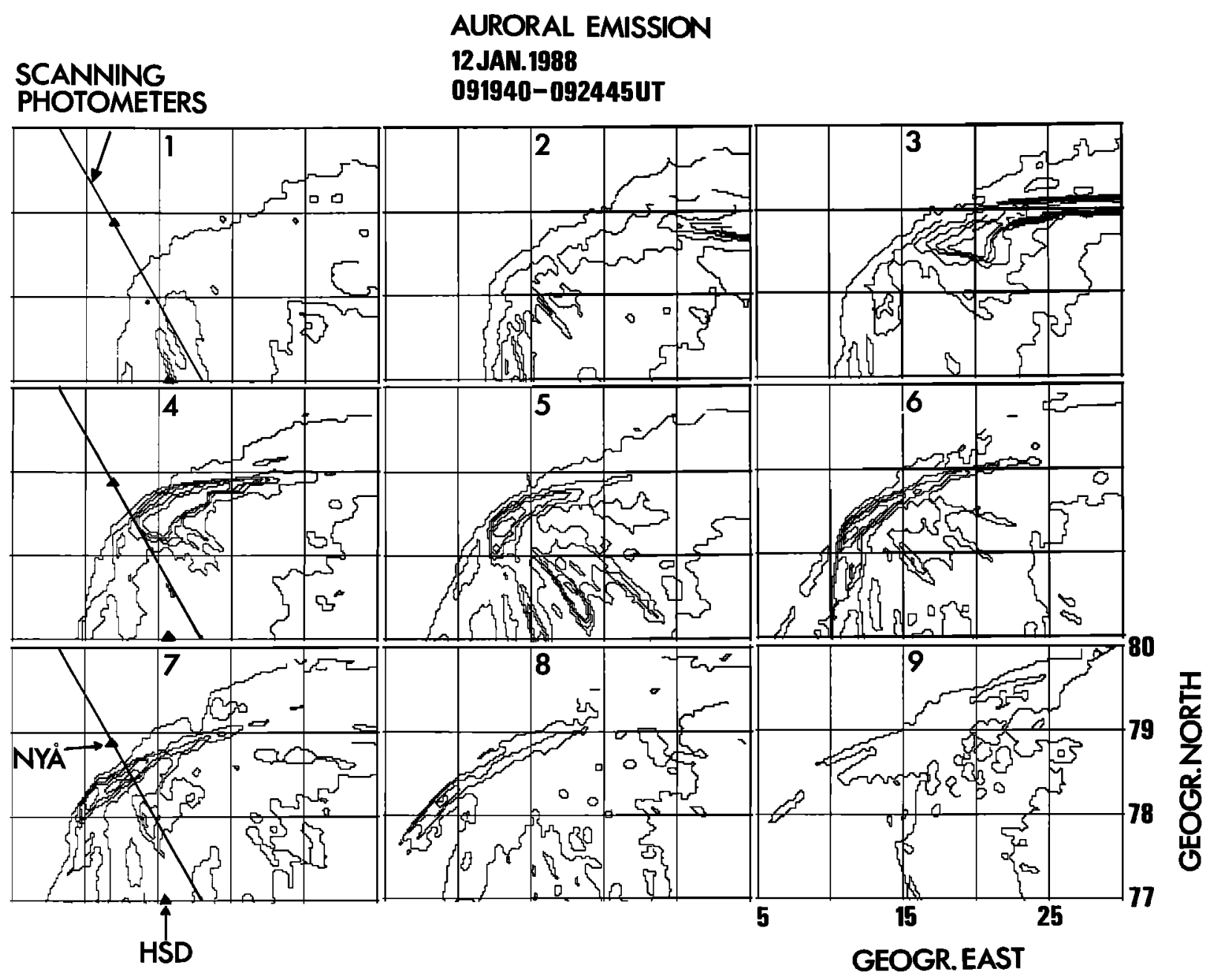

Fig. 3b. Auroral intensity contours in geographical coordinates for the picture sequence shown in Figure $3 a$, obtained from digital $T V$ images and assuming the lower border of the discrete aurora at $130 \mathrm{~km}$ altitude. The optical observation site at Ny Alesund (NYA) with the photometer scanning plane and the magnetometer stations at Hornsund (HSD) are marked in the figure.

to the westward ion velocity observed in the vector data for this range gate following the onset.

\subsection{All-sky TV Observations}

Figure $3 a$ shows a representative TV image sequence of the transient optical event initiated near $0920 \mathrm{UT}$. We notice a localized structure (arc fragment) appearing near the horizon in the east at 0920:17 UT (second frame). The location of the western edge of this structure is estimated to be $-200 \mathrm{~km}$ to the south and $\sim 300 \mathrm{~km}$ to the east of $\mathrm{Ny}$ Alesund, in geomagnetic coordinates, at 0920:17 UT. During the next minute the luminosity expanded toward the northwest and reached the photometer scanning plane at 0921:35 UT (cf. also Figure 2), with the peak 557.7-nm intensity at $28^{\circ}$ south of zenith. Both the moving transient and the cusp/cleft aurora further south are characterized by long field-aligned rays with sharp lower borders. The 0922:00 UT picture is seen to be most pronounced in this respect. By 0924:45 UT (last frame) the transient form reached its maximum east-west elongation, in the phase of fading intensity. The location was then slightly south of zenith.

Figure $3 b$ shows the same sequence in the form of auroral intensity contours in geographical coordinates. The plot is obtained from digitized TV images and is based on an assumed emission altitude of $130 \mathrm{~km}$. This means that the contours are relevant for the low-altitude, discrete auroral component only. From this plot we derived a westward propagation velocity of $3.1 \mathrm{~km} \mathrm{~s}^{-1}$ for the lower border of the leading edge of the transient structure, between 0920:55 (frame 3) and 0922:00 UT (frame 5). After this time the velocity decreased significantly. 
2.3. The Optical Events: Occurrence Frequency and Spatial Distribution

The two events presented in this paper (cf. Figure 2) are two of a series of nine similar events that occurred between 0900 and 1130 UT on January 12, 1988 [Lockwood et al., 1989, Figure 3]. The average recurrence time within the interval is then - $15 \mathrm{~min}$. After $1000 \mathrm{UT}$, IMF $\mathrm{B}_{2}$ was changing between negative and positive values, which contributed to a reduced occurrence frequency within the interval. Prior to 1000 UT, when IMF $\mathrm{Bz}_{2}$ was consistently southward, the recurrence period was 7 min.

During conditions similar to those for 0900-1000 UT (IMF $\left.\mathrm{Bz}_{2}\langle 0, \mathrm{BY}\rangle\right\rangle$ ) on November $24,1987,15$ events were recorded from the photometer profiles within 0615-0830 UT (0945-1200 MLT), corresponding to an average recurrence time of 9 min [cf. Sandholt et al., 1989a]. The quasi-periodic nature of the optical events is an important property which suggests a link with flux transfer events at the magnetopause. Rijnbeek et al. [1984] found that the mean repeat period of FTEs was $8 \mathrm{~min}$ for stable southward IMF. In most of the optical cases, characterized by lower auroral intensities than those analyzed here, clear ground magnetic signatures are not observed by visual inspection of the standard magnetograms obtained by flux gate instruments.

The local time distribution of the optical events, and the time history of one individual event (cf. also Figure 3), are schematically illustrated in Figure 4. This occurrence pattern is based on observations from one single ground station as it rotates with the Earth from prenoon to postnoon hours (i.e., it is not a snapshot). The initial phase

(breakup) is usually outside the field of view of the meridian-scanning photometers and is therefore not detected by that technique. All-sky TV observations provide the necessary complementary information, summarized by figure $4 \mathrm{~b}$. The TV observations are mainly sensitive to the green line (557.7 $\mathrm{nm}$ ) emissions and show that the luminosity tends to elongate in the east-west dimension during the rapid westward motion of the event (phase Isee Figure 7). The second poleward moving phase (II) is when the optical intensities fade.

\subsection{Meridian Chain Magnetometer Data}

Figure $5 a$ shows $H$ component magnetograms from Ny Alesund (NA), Hornsund (H), Bjørnøya (B), and Troms $\phi$ (T), located as indicated in Figure 1. The 0800-0900 UT (1130-1230 MLT) period was very quiet in terms of magnetic and auroral activities. A smooth negative (H component) bay is seen at Ny Alesund from - 0910 UT onward, while the corresponding deflection at (a)
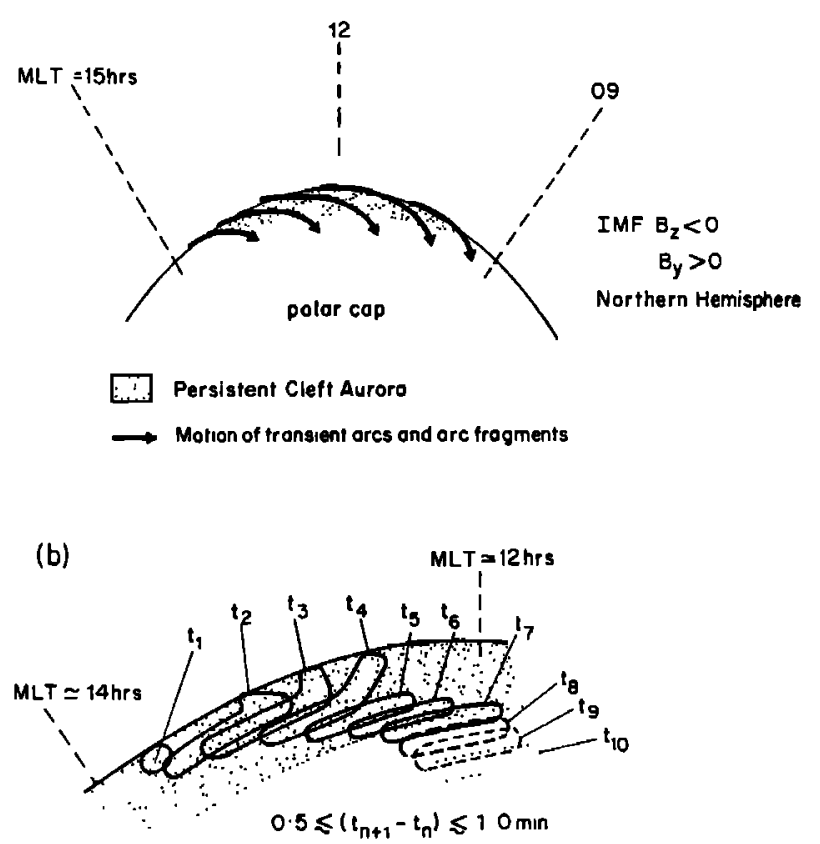

Fig. 4. Schematical illustration of (a) the local time distribution of the discrete optical events (solid curved arrows) as well as (b) the detailed time history of one individual event (09200927 UT on January 12, 1988). The auroral form appeared at time $t_{1}$ near the boundary of the field of view of the TV camera. Figure $4 a$ is based on observation from one single ground station as it moves with the Earth from prenoon to postnoon hours (not snapshot). The real recurrence time for these events is much shorter than indicated in the sketch.

Bjørnøya is positive. Maximum amplitudes - 100 nT are observed at both stations. The Troms $\varnothing$ trace shows a negative $H$ component, but weaker than at $\mathrm{Ny}$ Alesund. Positive $H$ component deflections are observed at Hornsund. These magnetograms indicate a rotational convection reversal near the meridian of the magnetometer chain, when taking into account all three components (Figures $5 b$ and $5 c$ ). Several short-lived pulses are superposed on this rather smooth DP2/DPY-like deflection. From the Ny Alesund (Figures $5 a$ and 5b) and Hornsund (Figure $5 \mathrm{c}$ ) traces we notice in particular the perturbations around 0910 and 0923 UT (marked by the two arrows), which corresponds to the transient optical events reported above (Figure 2). Positive $H$ deflections occurred at both stations. Peak values were $=40$ (0912 UT) and $30 \mathrm{nT}(0923 \mathrm{UT}$ ) at $\mathrm{Ny}$ Alesund and 35 and 75 nT at Hornsund, after subtracting the background perturbation. In the 0912 UT case, $\Delta \mathrm{Z}=0$ at $\mathrm{Ny}$ Alesund and $30 \mathrm{nT}$ at Hornsund, indicating the discrete aurora near zenith at Ny Alesund to be the source of the deflection. At 0922- 


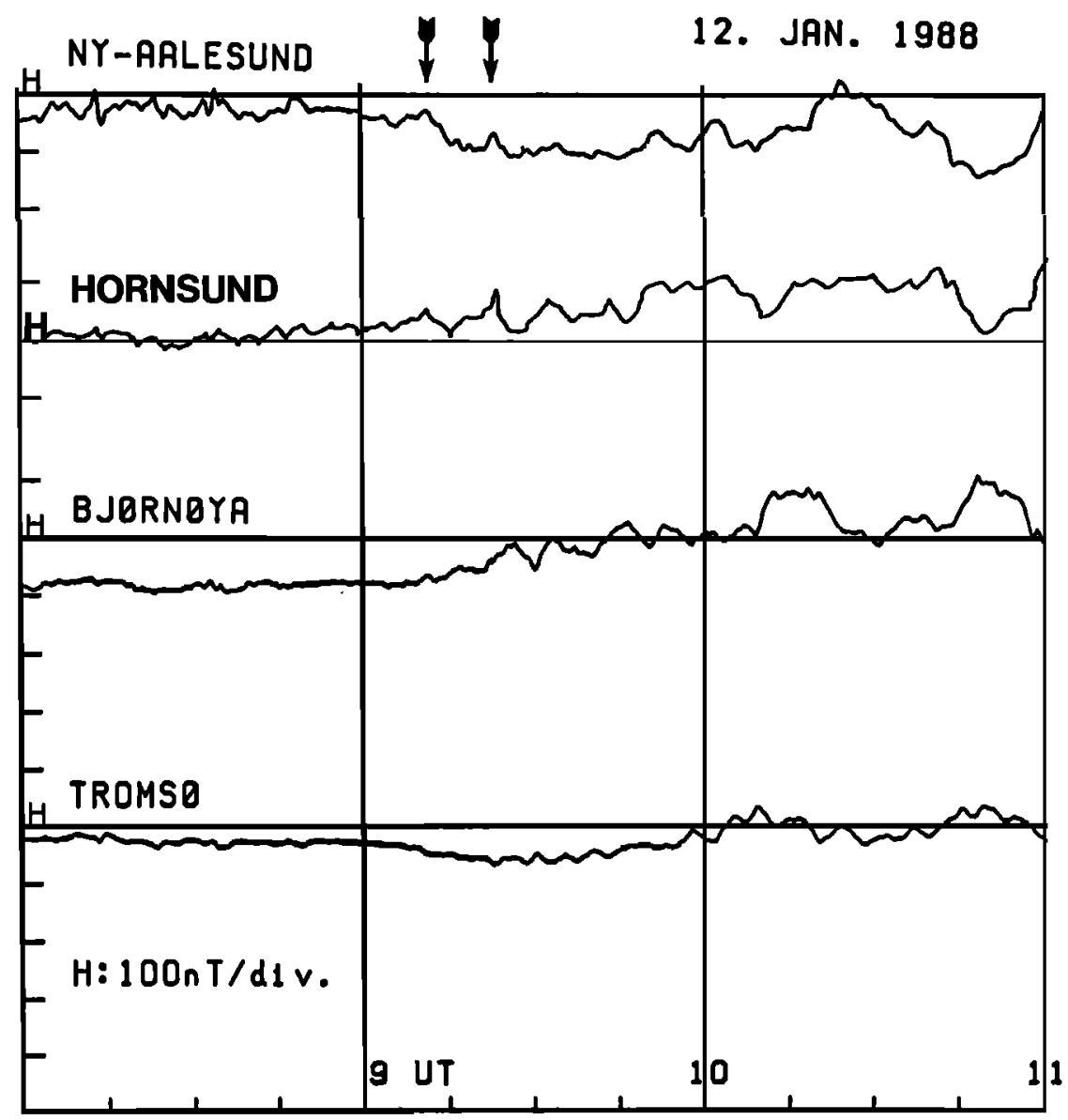

Fig. 5a. Horizontal component magnetograms from Ny Alesund, Hornsund, Bjørnøya and Tromsø (cf. Figure 1 for locations) with arrows marking two major optical/radar events discussed in the text.

0923 UT, $\Delta \mathbf{Z}$ is negative at NY Alesund $(-45 \mathrm{nT})$ and positive at Hornsund $(75$ nT), consistent with a Hall current filament associated with the discrete aurora located between the two stations (cf. Figure 3b). Further analysis of the magnetic deflection during the 0920 UT event is given in the appendix.

\subsection{IMF Data}

Fifteen-second-averaged IMP 8 IMF data (cf. Figure 6) reveal a stable total field intensity (15-18 nT) during the 0600 to 1135 UT interval on January 12 , 1988. IMF $\mathrm{Br}_{2}$ (GSM coordinates) was invariably negative between 0805 and 0950 UT. Both the $\mathrm{Bz}_{2}$ and $\mathrm{By}_{\mathrm{y}}$ components were increasing between 0900 and 0930 UT, from - 8 to - $3 \mathrm{nT}$ and from 11 to $16 \mathrm{nT}$, respectively. Bx values between - 7 and$12 \mathrm{nT}$ were observed. The total field was approximately constant, between 17 and 18 $\mathrm{nT}$, during this interval. We notice two shorter intervals of significant IMF reorientations, superposed on the general, slow trend during this period, at 0906-0908 and 0916-0919 UT, characterized by IMF $\left|\mathrm{Br}_{\mathrm{y}} / \mathrm{Bz}\right|<1(\triangle \mathrm{Br} \sim-7 \mathrm{nT})$ and 3
$\left(\Delta \mathrm{Bz}_{2}-5 \mathrm{nT}\right)$, respectively. The IMF was observed at a satellite location of $\mathrm{XSM}_{\mathrm{M}}=$ - $4.5 R_{E}, Y_{S M}=-33 R_{E}, \mathrm{ZSM}_{\mathrm{S}}=8 \mathrm{RE}$, for which the satellite to ionosphere lag is estimated to be less than 5 min.

\section{Discussion}

3.1. Coordination of the Optical, Geomagnetıc, Ion Drift and IMF Observations

The main characteristics of the optical and geomagnetic aspects of the 09090912 and 0920-0925 UT events (within the 1230-1300 MLT interval) on January 12, 1988, are their small-scale, transient, quasi-period nature and their location near the polar cap boundary. The first, short-lived structure moved nearly due north, whereas the second showed a strong westward component. In both cases the auroral structure had a velocity very similar to the vector ion drift obtained in the radar gates closest to it. Their spiky magnetic signatures are superposed on a more large-scale, smooth trend, i.e., DP2/DPY mode deflections associated with the dayside region 1 current and 


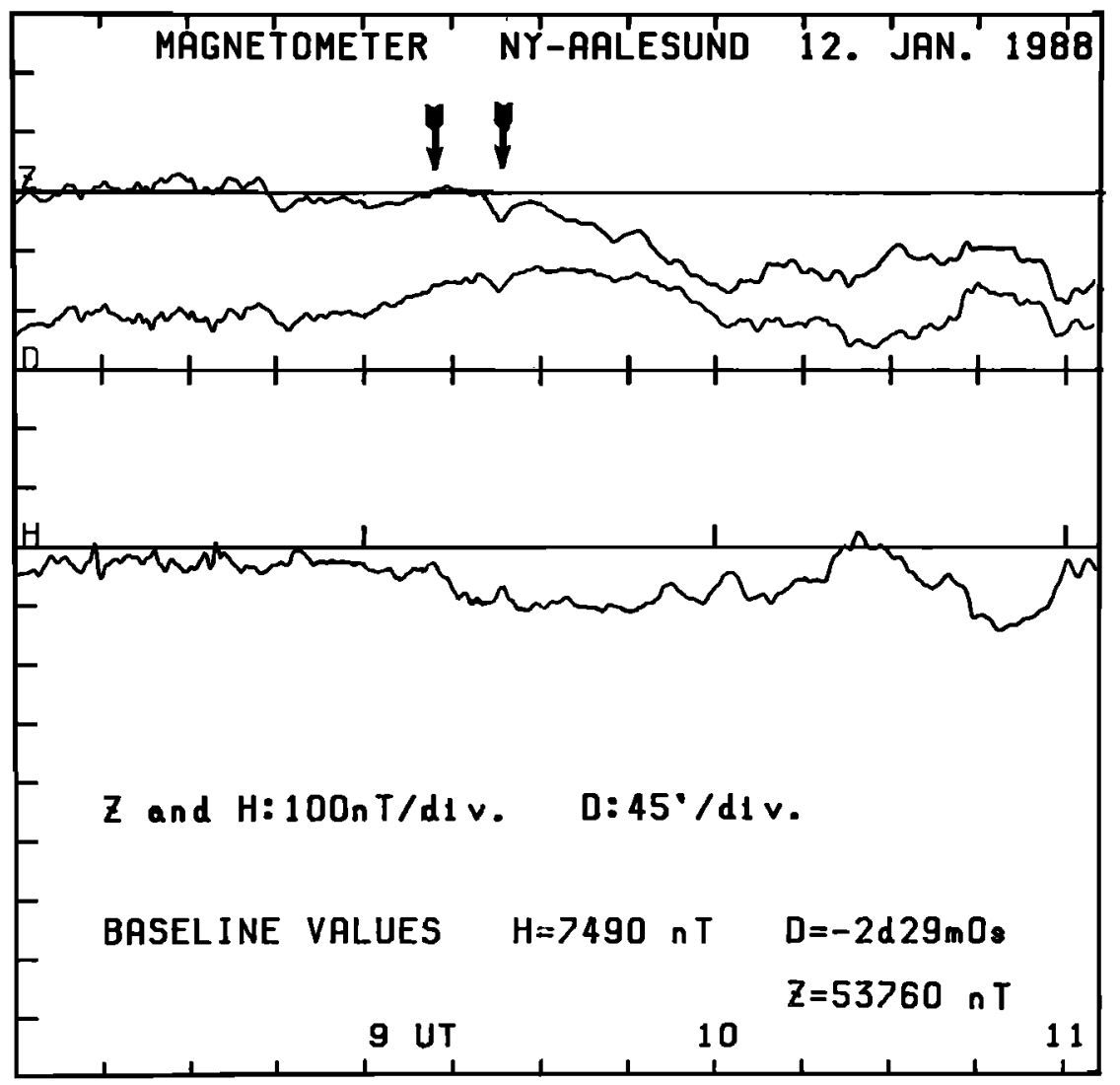

Fig. 5b. Z, D, and $\mathrm{H}$ component magnetograms from $\mathrm{NY}$ Alesund.

cusp system. The discrete spatial structures as well as the spectral properties of the optical emission (cf. appendix) strongly indicate the existence of associated filamentary field-aligned currents, in addition to the more largescale region 1 cusp currents, associated with the persistent cusp auroral arc. In this section, we combine these data to understand the field-aligned current structures and the momentum they may transfer to the ionosphere during these transient events (Southwood, 1989). A peak value of ${ }^{-} 1 \mathrm{keV}$ for the precipitating electron flux average energy is derived from the photometric intensities within the discrete structure at 0921:50 UT (cf. appendix). The spatial scale of the optical arc observed by the TV (predominantly at $557.7 \mathrm{~nm}$ ) during $0922-$ $0923 \mathrm{UT}$ is $500 \mathrm{~km}$ (east-west) times $50 \mathrm{~km}$ (north-south). Electron energy fluxes " 1-10 ergs $\mathrm{cm}^{-2} \mathrm{~s}^{-1}$ and average energies 0.5-1 keV within this region are indicative of significant upward directed field-aligned current [cf. Sandholt et al.. 1989b]. The details of the inferred filamentary current structure are not known in this case since no direct measurements of field-aligned currents are available. However, measurements from the HILAT satellite during a similar event (in terms of local time, electric field, optical emissions, and IMF orientation) did show pairs of small-scale upward and downward directed currents, superposed on a larger-scale region 1 current collocated within the cusp electron precipitation [cf. Sandholt and Egeland, 1988;

\section{HORNSUND 12 JAN.1988}

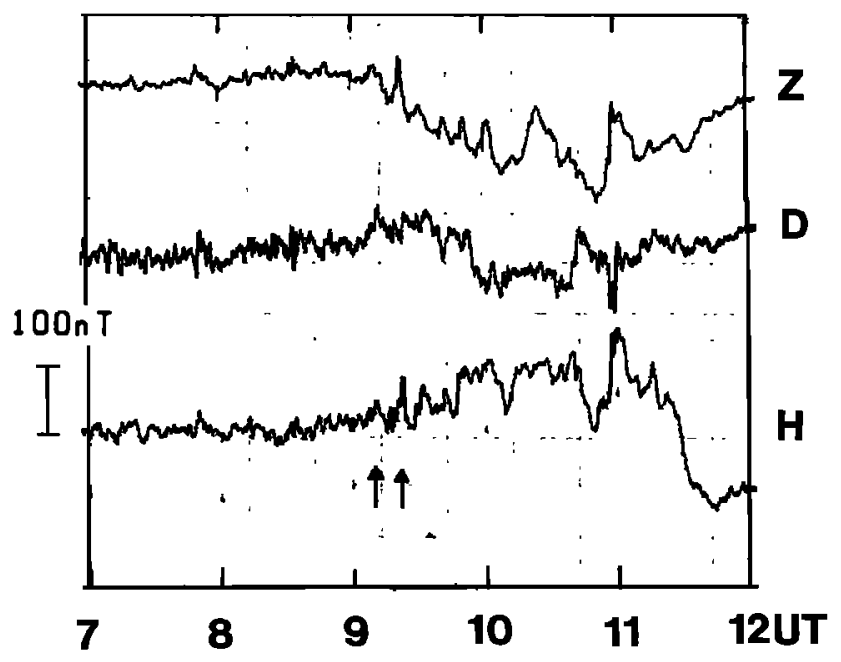

Fig. 5c. $Z$, D, and $H$ component magnetograms from Hornsund. Arrows mark two major optical/radar events discussed in the text. 
IMP-8 IMF DATA

12 JAN. 1988
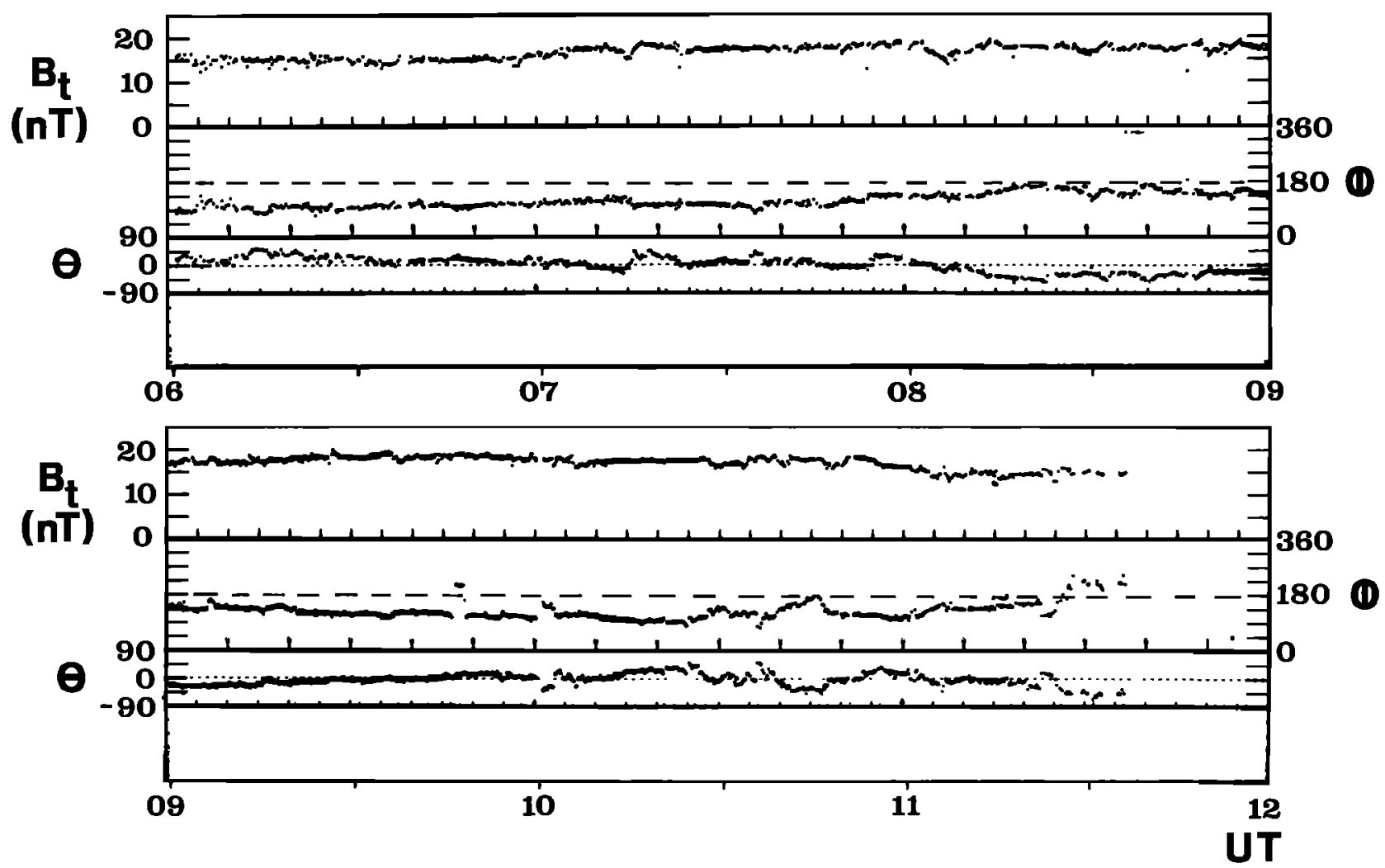

Fig. 6. IMP 8 IMF data: from top to bottom, total field (Bt), and IMF orientation expressed in GSE azimuth $(\phi)$ and latitude $(\theta)$ angles.

Sandholt et al., 1989b]. The oppositely directed field-aligned current filaments were connected by a northward ionospheric Pedersen current in that case. Current amplitudes - $10 \mathrm{LA} / \mathrm{m}^{2}$ were inferred for these filaments from the HILAT magnetometer data. Electron precipitation energy fluxes ${ }^{-}$5-10 ergs $\mathrm{cm}^{-2} \mathrm{~s}^{-1}$ and northward electric fields $200 \mathrm{mv} \mathrm{m}^{-1}$ were observed within the structures. The optical intensities in this HILAT case were -1 and $5 \mathrm{kR}$ at $557.7 \mathrm{~nm}$ and $630.0 \mathrm{~nm}$, respectively, which are comparable with the intensities measured in the late phase of the second of the two events studied here (0923:00 UT); however, in the maximum phase (- 0921:50 UT), higher intensities and somewhat different optical spectral composition were observed, indicating a harder electron distribution. Another difference between the HILAT case and the present events should be noticed. The former structures are totally confined within the latitudinal range of the cusp persistent arc and the coincident dayside region 1 current system. They do not move north of the cusp poleward boundary, as the present structures do. As discussed later, we infer that a larger transient potential difference between the magnetopause and the ionosphere forms during the events studied in the present paper.
The Ny Alesund and Hornsund magnetograms for the 0920-0925 UT event show positive $\Delta H$ and opposite polarities of the $\mathrm{Z}$ component of the deflection, superposed on the smooth background perturbation, indicating an eastward Hall current filament consistent with westward ion flow observed by EISCAT between the two stations. The peak current amplitude was probably located within the discrete auroral arc fragment observed 50-100 km south of Ny Alesund. The height-integrated Hall conductance within the arc, in the photometer scanning plane, changed from 3 mhos at 0921:50 UT to 0.5 mho at 0923:00 UT, as determined from the photometer intensities. Fair agreement was found between the calculated and observed magnetic deflection at Ny Alesund (cf. appendix). In this calculation we used $\sum$ $=1$ mho as an average value within the 70-s interval, $E_{N}=150 \mathrm{mV} / \mathrm{m}$, obtained from radar gates 6-8, to model the effect of the zone of enhanced Hall current covering the latitudinal range from 50 to $250 \mathrm{~km}$ south of $\mathrm{Ny}$ Alesund, comprising both the isolated discrete arc and the intensified cusp emission further south (cf. Figure 2).

During the 0910-0912 UT (- 1230 MLT) event, corresponding to IMF $\left|\mathrm{Br}_{\mathrm{B}} / \mathrm{Bz}_{\mathrm{z}}\right|<1$ $\left(B_{2}=-8 \mathrm{nT}\right)$, the discrete optical 
aurora occurred as a thin sheet elongated in the east-west direction. This form moved poleward at a speed of $1.2 \mathrm{~km} \mathrm{~s} \mathrm{~s}^{-1}$, comparable with the ion drifts measured at the radar gates closest to the structure (peak vlos for gates 4 and 5 were 1.1 and $1.3 \mathrm{~km} \mathrm{~s} \mathrm{~s}^{-1}$, away from the radar). Also notice the short duration of this event, $i . e .$, fading away after $2.5 \mathrm{~min}$. This is in good agreement with the predicted ionospheric signatures of FTEs at local noon (see Lockwood and Cowley [1989] and section 3.2 below).

A latitudinal zone of enhanced westward ion flow was observed to be collocated with the persistent cusp aurora in the interval - 0918-0925 UT, when the IMF was characterized by $\left|\mathrm{By} / \mathrm{Bz}_{2}\right|$ between 2 and 3. A significant increase of the westward flow velocity occurred between radar gate 4, near the cusp equatorward boundary, and gate 7, during 0917-0930 UT (cf. Figure 2). The corresponding northward $E$ field gradient, $100 \mathrm{mV} \mathrm{m}^{-1}$ across a latitudinal distance 50 to 200 $\mathrm{km}$ is consistent with downward directed field-aligned current in that region, according to the current continuity equation. Under the actual conductivity conditions, i.e., moderate gradients in the region of the persistent cusp arc, this equation is given by the following approximation:

$$
j_{\mid l}=\Sigma_{\mathrm{P}} \delta \mathrm{E}_{\mathrm{X}} / \delta \mathrm{X}
$$

where $\mathrm{X}$ denotes distance in the northward direction. A field-aligned current amplitude $-1 \mathrm{\mu A} / \mathrm{m}^{2}$ is derived for the present case, corresponding to an estimated $\overline{\mathrm{L}} \mathrm{P}$. 2 mhos within the persistent cusp arc and the $E$ field gradient given above. According to this interpretation, a downward field-aligned current with large temporal variation, related to the $E$ field gradient in Figure 2, is collocated with the persistent cusp auroral arc. The location and direction of this current are consistent with a recent statistical study of the region 1 current pattern near noon [cf. Erlandson et al., 1988]. Downward region 1 current is expected at cusp/ cleft latitudes at 1300 MLT, during strongly positive IMF Br conditions.
The drift velocity of the discrete auroral structure/current filament to the north of the persistent cusp arc was found to be comparable with the ion drift velocities measured in radar gates 6-8 during the 0921-0923 UT interval. The observed $3-\mathrm{km} \mathrm{s}^{-1}$ westward drift is in the same direction as the westward (main component) jpxB force related to the northward ionospheric Pedersen current ( $\left.j_{p}\right)$ within the auroral/current filament. This force balances the frictional force associated with ion-neutral collisions. The energy transfer to the ionosphere in the form of Joule heat dissipation is given by

$$
U_{J}=\vec{j} \times \vec{B} \cdot \vec{v} \sim{ }_{E}-E_{X}=\sum_{P} E^{2}
$$

where $V_{E}=(\operatorname{ExB}) / B^{2}$.

By inserting the maximum $\sum P$ value $(\approx 5$ mhos), obtained at 0921:50 UT (cf. Table 1 and appendix), and $E_{x}=150 \mathrm{mV} / \mathrm{m}$, we obtain for the corresponding Joule heat dissipation rate $U_{J}=0.1 \mathrm{~W} \mathrm{~m}^{-2}(100$ ergs $\left.\mathrm{cm}^{-2} \mathrm{~s}^{-1}\right)$. Taking the area to be $50 \mathrm{~km}$ by $500 \mathrm{~km}$, it alone is hence associated with a total power of - $10^{9} \mathrm{~W}$, a factor of 10 larger than that due to particle precipitation (cf. appendix).

The northward electric field within the east-west elongated arc, during quasi-steady state conditions, is given by [Marklund, 1984]

$$
E_{X}^{A}=\frac{\Sigma_{P}^{E}}{\Sigma_{P}^{A}} E_{X}^{E}+\frac{\Sigma_{H}^{A}-\Sigma_{H}^{E}}{\Sigma_{P}^{A}} E_{Y}^{E}+\frac{J}{\Sigma_{P}^{A}}
$$

where superscripts $A$ and $E$ denote quantities measured within and outside the arc. respectively. Equation (3) is based on current continuity at the equatorward boundary of an elongated slab of enhanced conductivity associated with the auroral arc.

In general the last term in (3) is the major one in the cusp, i.e., most cusp arcs are Birkeland current arcs, accord-

\begin{tabular}{|c|c|c|c|c|c|c|}
\hline Time, UT & $\begin{array}{c}\text { I (630.0), kR } \\
\text { (Zenith } \\
\text { Angle) }\end{array}$ & $I(427.8), \mathrm{kR}$ & $\begin{array}{l}\text { Electron } \\
\text { Energy, } \\
\text { kev }\end{array}$ & $\begin{array}{l}\text { Electron } \\
\text { Energy F1ux, } \\
\text { ergs } \mathrm{cm}^{-2} \mathrm{~s}^{-1}\end{array}$ & $\sum_{\text {(mhos }}$ & $\sum^{\mathbf{E}}$ \\
\hline \multirow[t]{2}{*}{$0921: 50$} & 6.8 & 1.6 & 0.5 & 8 & 6.6 & 3.0 \\
\hline & $\left(27^{\circ} \mathrm{sz}\right)$ & $\left(28^{\circ} \mathrm{sZ}\right)$ & & & & \\
\hline $0923: 00$ & $\begin{array}{c}4.5 \\
\left(18^{\circ} \mathrm{sz}\right)\end{array}$ & $\begin{array}{c}0.5 \\
\left(23^{\circ} \mathrm{sz}\right)\end{array}$ & 0.2 & 2.5 & 1.7 & 0.4 \\
\hline
\end{tabular}
ing to the terminology introduced by

TABLE 1. Discrete Aurora and Ionospheric Conductances 
Marklund [1984]. Polarization electric fields usually play a minor role in this region, as is evident from the character of the ground magnetic field deflections. In the discrete arc discussed here (0921-0923 UT) the first term in (3) could be a significant fraction of the Birkeland current term, due to the relatively large background values of $\bar{L}_{P}$ and Ex. During the transient magnetometer deflections, observed in association with the discrete, transient cusp auroral structures, some contribution may even be due to the second term in (3), but this term is invariably minor for the large IMF $\left|\mathrm{By}_{\mathrm{Y}} / \mathrm{Bz}_{\mathrm{z}}\right|$ cusp cases, characterized by $E_{Y}<E_{X}$.

A crucial question concerning the relationship between the ion flow observations and the optical events is the closure of the net downward current inferred at cusp latitudes south of the discrete arcs. The observed relationship between the temporal changes in the ion flow pattern and the optical events indicates a direct connection between the two phenomena [Lockwood et al., 1989, Figure 3]. Figure 7 schematically illustrates the relationship between the ion flows, auroral structures, and the inferred filamentary field-aligned currents discussed above. Figure $7 \mathrm{~b}$ is a schematic of an event, which initially moves westward (phase I), before noving poleward (phase II), from which we predict variations in potentials across the radar field of view, $R$, ( $\Phi$ f $n$ and te corresponding to westward and northward flow, respectively) of the type shown in Figure $7 a$, relative to the passage of the discrete auroral structure through the photometer scan, P. Most of the optical events observed between 0900 and 1130 UT were indeed preceded by enhancements in the cross cusp/cleft potential drop, or at least that part of it within the radar field of view, $\Phi \mathrm{fn}$ (cf. the 0920 UT event in Figure 2) as predicted in Figure $7 \mathrm{a}$. such enhancements are therefore consistent with the onset of localized fieldaligned electric fields and the auroral brightenings, as indicated in Figure $7 \mathrm{c}$.

The peak of the longitudinal potential drop inferred between the two radar azimuths (申fe) usually lags the $\phi \mathrm{f}$ (north-south potential) peak, as shown in Figure 7a, based on the observations reported by Lockwood et al. [1989]. This pattern is consistent with a dominating westward drift component in the early phase of the event, with subsequently increasing northward drift component in the fading phase, corresponding to an increased tilt of the flow pattern (cf. Figure 7b). The 0920-0925 UT case $(\Delta \mathrm{H})$ $0, \Delta D<0)$ is explained by a strong and long-lived phase $I$, followed by a weaker phase II. The negative $Z$ deflection at 0920-0925 refers to a current filament to the south of Ny Alesund.

It is interesting to note that Figure $7 \mathrm{~b}$ predicts that the onset of an event (a)

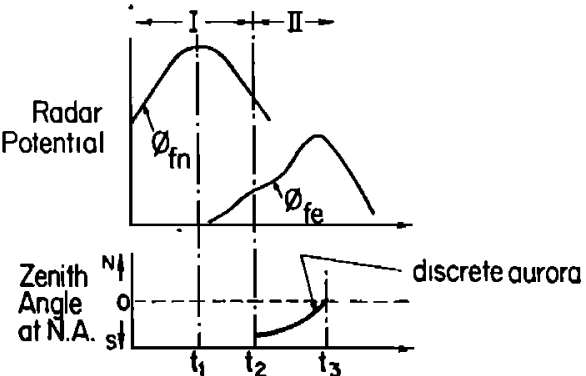

(b)

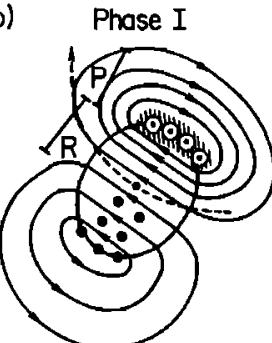

Phase II

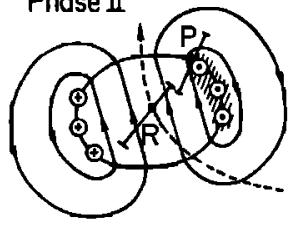

$\stackrel{R}{P}$ Rodar field of view

Photometer scan

Motion of event center

(c)

"IIIII, Discrete ouroro

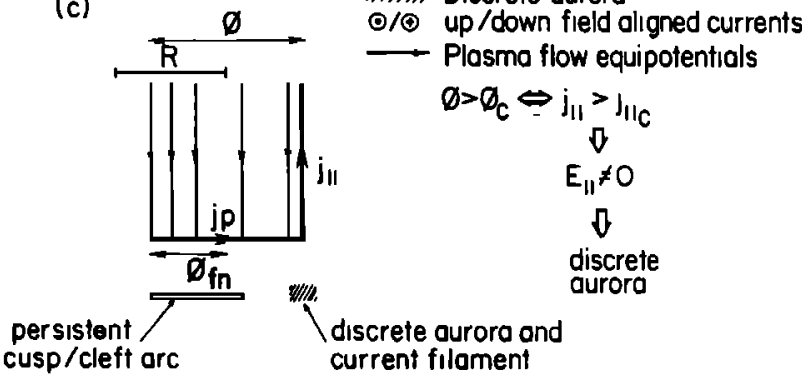

Fig. 7. (a) sketch of typical time development of latitudinal $(\phi \mathrm{f})$ and longitudinal ( $\phi_{\mathrm{fe}}$ ) potential drops across the radar field of view as well as scanning photometer trace of the simultaneous discrete aurora. $t_{1}$ and $t_{2}$ mark auroral breakup and subsequent photometer intensification, respectively. (b) Two simplified snapshots of ion flow pattern and relationship with discrete auroral arc in two phases during a typical event (compare Figure 7c). Radar field of view and photometer scanning plane are marked in the figure. (c) Meridian cross section of the cusp/cleft region with downward field-aligned current (IMF $B_{y}>0$ ) in the persistent arc and filamentary current system coupled with the discrete, transient aurora further north.

for $B y>|B z|$ (strong phase I) slightly to the south of the radar (as shown) would give initially weak northward flow at $R$, prior to the strong westward flow. However, this will be superposed on the flow caused by phase II of the preceding event, which is also northward. If, however, the event center were initially immediately north of the radar, the onset of phase I would give weak southward flow. This would detract from the northward flow caused by phase II of the previous event. Therefore radar and 
magnetometer signatures of these events are complicated by the fact that they do not tend to occur in isolation but rather in a sequence and only a few minutes apart.

3.2. Relationship With Coupling Between the Solar Wind and Magnetosphere and the Associated Momentum Transfer

The two model categories of solar wind-magnetosphere coupling at the dayside magnetopause with most relevance to the present work are the so-called boundary layer dynamo model and the merging/reconnection models. As pointed out by Cowley [1986] and Lundin [1987] neither of these descriptions seems to exclude the other.

The boundary layer model assumes the existence of an injected dynamo plasma [cf. Lemaire, 1977; Schindler, 1979], generating an electric field which is considered to be responsible for, e.g., acceleration of auroral particles and for powering the dayside region 1 current system, with the associated energy dissipation in the dayside auroral oval ionosphere [Lundin, 1984; Meng and Lundin, 1986; Lundin, 1987]. Baumjohann and Paschmann [1987] noted that any such interaction has aspects of both reconnection and viscouslike interactions, but is by its nature a nonsteady process.

Several investigations indicate that viscouslike interactions at the magnetopause boundary layer cannot explain the large cross polar cap potentials observed during negative IMF $B_{2}$ intervals le.g.. wygant et al. [1983], Mozer [1984], and reviews by Cowley $[1982,1984]$, and Baumjohann and Paschmann [1987]).

According to the quasi-steady state reconnection concept (e.g.. reviews by Axford [1984], Sonnerup et al. [1981]. Cowley [1982, 1984], and Paschmann et al. [1986]), when applied to the dayside magnetopause, the convective flow and associated dayside region 1 current system are driven by the solar wind electric field applied to an extended $x$-type neutral line at the magnetopause [cf. Stern, 1983; Saunders, 1989].

Southwood [1987] considered the possibility that patchy or sporadic reconnection (cf. review by Galeev et al.

[1986]), as evidenced by FTEs, at times could be the dominant mode of momentum transfer. This suggestion is strengthened by Galeev et al. [1986], who considered a localized spontaneous process to be much more general and typical for the magnetopause than quasi-stationary reconnection [cf. also schindler, 1979]. According to the model of Southwood [1985, 1987], based on the Russell and Elphic [1979] concept, FTE-related isolated current tubes generate a twin vortex ionospheric flow pattern convecting through the dissipative ionosphere. The jxB force associated with the Pedersen current in the central part of the tube, fed by field-aligned currents along the tube flanks, balances the frictional force due to ion-neutral collisions. The typical ionospheric scale size of the FTE-related tube should be a few hundred kilometers, based on a simple flux mapping from the magnetopause and flux conservation.

Alternative FTE concepts have been presented by southwood et al. [1988] and Scholer [1988], arguing that enhancement and subsequent reduction in the reconnection rate could give rise to elongated shells of connected field lines which are consistent with the observed magnetopause FTE signatures. In these models there is nothing to determine the longitudinal scale size at the magnetopause. A similar longitudinal elongation at ionospheric heights is expected. An elongated FTErelated plasma configuration is also discussed by Lee and Fu [1985] and Lee et al. [1988], related to their multiple $x$ line reconnection model.

Another FTE model with ionospheric predictions of relevance to the present observations has been reported by Kan [1988]. FTEs are proposed to be initiated by a three-dimensional tearing of the magnetopause current sheet, with the intermittent nature determined externally by IMF fluctuations and internally regulated by the ionospheric line-tying effect. Among the inferred ionospheric signatures are intense, multiple, elongated field-aligned current sheets and associated auroral arcs fanning out from the cusp region along enhanced convection channels, resulting in spiky electric field latitude profiles. The convection channel predicted by this model is different from the southwood model since no convection reversal is introduced. Kan [1988] notes that the current intensity of the paired FTE field-aligned currents need not be equal. Quite to the contrary, a net field-aligned current is expected in order to account for the twisted field lines [Wright, 1987] indicated by the magnetopause observations [Saunders et a1., 1984]. Related to this, we note that the HILAT case presented by Sandholt and Egeland [1988] indicates small or zero net field-aligned current associated with transient and quasi-periodic cusp structures similar to those discussed here.

Moses et al. [1988] reported on DE 2 ion flow observations and model calculations of electric field concentrations along portions of the dayside polar cap boundary, collocated with cusp particle precipitation, which they call multiple "throats". They note that the transient, discrete auroral structures reported by Sandholt et al. [1986a] may well correspond to these electric field concentrations; both signatures are considered possibly FTE-related.

We consider the characteristics of the dayside auroral breakup events, reported here and elsewhere (cf. introduction) (i.e., the spatial and temporal scales, the quasi-periodic nature, the pattern of 
motion relative to the persistent cusp or cleft auroral arc, the strong relationship with the IMF orientation, the associated ion flow/E field events as well as the magnetic signatures), to be strong evidence in favor of a transient, intermittent reconnection process at the dayside magnetopause that constitutes a plasma field entity along which energy and momentum is transferred from the magnetosheath to the ionosphere in the polar cusp and cleft regions. From the present observed cases we note in particular the following points:

1. The motion pattern and the lifetime of the events seem to be determined by the IMF $\left|B_{Y} / B_{2}\right|$ ratio, i.e., the optical/radar events show due poleward motion, during IMF $\left|B_{Y} / B_{2}\right|<1$ intervals, and are more short-lived than those with dominating longitudinal motion, occurring during IMF $\left|\mathrm{BY}_{\mathrm{Y}} / \mathrm{Bz}\right|>1$ periods. This patcern agrees well with model predictions of the period of time during which newly opened flux tubes related to transient reconnection will impart momentum to the ionosphere, depending on their direction of motion. Flux tubes that move poleward into the polar cap do seem to wrap themselves sooner over the front of the lobe and hence impart momentum for a shorter time than those moving along the polar cap boundary [cf. Southwood, 1987; Lockwood and Cowley, 1989; Lockwood et al.. The excitation of ionospheric convection, submitted to Journal of Geophysical Research, 1988 (hereinafter Lockwood et al., submitted manuscript,

1988 ) ]. However, study of a larger number of events is needed in order to be conclusive on this point.

2. The discrete auroral luminosity seems to persist for as long as the predicted momentum transfer (2-10 min) and indicates the existence of - 1-kV potential drops between the magnetopause and the ionosphere, located near the flow reversal associated with the polar cap boundary. It is also interesting to notice that the red line emission also fades away when the momentum transfer stops. This could well be because the flow at the magnetopause turns superAlfvenic, implying that the sheath particles can no longer reach the ionosphere down the open flux tube [Reiff et al., 1977]. The geometrical limitation on the particle access to the ionosphere applies directly only to ions since the electron thermal velocities are far above the tailward convection speed. However, as charge quasi-neutrality is generally obeyed in the cusp [Burch, 1985], the region of intense electron flux entry is normally limited to the ion entry region [cf. Newell and Meng, 1987]. This observation strongly supports the notion that the cleft/cusp particles generate the conductivity which enables the ionosphere to extract momentum from the magnetosheath flow via field-aligned currents along newly connected flux tubes [P. H. Reiff, private communication, 1988]. That momentum is only coupled into the ionosphere in this relatively narrow region has recently been deduced by Lockwood et al., submitted manuscript, 1988 and Lockwood and Cowley [1989] from the rapid response of convection to changes in the IMF, observed using EISCAT and AMPTE.

3. Fast westward motion was observed in the early phase of the 0920-0925 UT $1^{-} 1300$ MLT) event, after the initial breakup near the cusp equatorward boundary. This fits well with the predicted field tension force for positive IMF $B Y$. After a few minutes the westward motion decreased (cf. Figure 3), followed by mainly poleward drift in the fading phase of the arc, consistent with the effect of antisunward magnetosheath flow becoming increasingly important, as predicted by Saunders [1989].

4. The longitudinal elongation of the optical events, i.e., $500 \mathrm{~km}$ eastwest times $50 \mathrm{~km}$ north-souch, is in good agreement with the sheet geometry in Kan's model or in models of the effects of variations in reconnection rate

[Southwood et al., 1988; Scholer, 1938] or of multiple $X$ lines [Lee and $F u, 1985$; Lee et al., 1988]. In the isolated flux tube rodel by Southwood [1987] the optical signature is expected to be coincident with the upward field-aligned current at the poleward boundary of the central ion flow region. This means that the discrete optical structure could represent a rather smali fraction of the total latitudinal extent of the event, as is indicated by the simultaneous radar observations presented here and by Lockwood et al. [1989] (cf. also point 8).

5. Enhancements in the latitudinal potential drop across the radar field of view with peak values $\sim 40-50 \mathrm{kV}$ during IMF $\left|\mathrm{Br}_{\mathbf{Y}} / \mathrm{B}_{2}\right|>1$ intervals, coincident with the occurrence of the filamentary auroral field-aligned current structures, could be associated with temporal and spatial variations in the more largescale region 1 current-cusp current system or more directly related to the discrete aurora, i.e., by constituting different elements of the FTE-related flux cubes proposed by southwood [1987]. During cases characterized by IMF $\left|B_{y} / B_{2}\right|$ $<1$ and poleward auroral and ion velocities 1-1.5 km/s, potential drops 25$35 \mathrm{kV}$ are inferred along the elongated arcs. Assuming the auroral arcs are associated with FTE flux tubes and that the luminosity marks their longitudinal scale, these potentials should be closely related to the FTE potentials.

6 . The magnetic signatures of the 0910 and 0920 UT events reported here show monopolar $\mathrm{H}$ component deflections related to Hall current filaments located near the discrete arcs. This observation could seem to be in favor of the sheet current model by Kan [1988]. However, a 
more large-scale twin vortex convection pattern with less distinct magnetic signatures is usually involved. Bipolar H component deflections, indicating convection reversals, and the additional signatures consistent with the southwood [1987] flow pattern [cf. also McHenry and Clauer, 1987], are observed when the movement of the structure relative to the station is favorable, as in the December 10,1983 , case shown in Figures $A 1$ and $A 2$ [cf. also Oguti et al., 1988]. We note that it is not surprising that the magnetic deflections do not look exactly like the predictions of McHenry and clauer [1987]. The reasons are revealed by these combined radar-photometer-TV camera data, namely: events cause major changes in conductivity distributions which are also far from uniform; events have a two-phase motion, and not a uniform motion over the magnetometer; and events are sufficiently closely spaced that their effects are superposed (i.e., their repetition period can be less than the period for which they impart momentum to the ionosphere).

7. The recurrence time (3-15 min) and the local time distribution $f^{*}$ 0900-1500 MLT) of the dayside auroral breakup events [cf. Sandholt et al.. 1989a], combined with the above information on the related ion drift events, indicate the important contribution of the polar cusp and cleft regions in the overall momentum and energy transfer between the solar wind and the magnetosphere. For example, Lockwood et al. [1989] deduced that the event at $1050 \mathrm{UT}$ is associated with a potential of at least $80 \mathrm{kV}$. Here we have deduced that the optical structure alone is associated with a power of over $10^{\circ} \mathrm{W}$, deposited as Joule heating. In addition to dayside transient reconnection, other mechanisms could play an important role at the tail flanks, contributing to the total energy and momentum transfer to the magnetosphere (T. Oguti, Questions on the dayside reconnection in connection with maganetospheric convection and open-closed boundary, submitted to Journal of Geomagnetism and Geoelectricity, 1988].

8. Allowing for propagation delays between the IMP 8 satellite and the ionosphere, it is possible that the 0910 and 0920 UT events could have been initiated by changes of the orientation of an IMF of constant amplitude, the IMP 8 satellite having observed temporary southeastward and northward excursions (Bz still negative), respectively. These observations could be consistent with the idea that FTEs are associated with changes in the reconnection rate, caused by IMF fluctuations, as proposed by Kan [1988], Southwood et al. [1988] and Scholer [1988]. However, we note that studies of FTEs at the magnetopause have nearly always failed to find such IMF triggers and hence the variations in reconnection rate and the recurrence period have been thought to arise from an internal "magnetospheric clock", rather than from structure in the IMF. If anything, the observations presented here imply that the internal clock may "lock on" to IMF changes if they are almost separated by the natural internal recurrence period of $-8 \mathrm{~min}$ [Rijnbeek et al., 1984].

\section{Summary}

Despite the considerable effort that has been made in the search for ionospheric signatures of flux transfer events in recent years, definitive experimental evidence has been difficult to obtain, although ion drift events [Cf. Goertz et al., 1985; Todd et al., 1986, 1988a], optical observations [Sandholt et al., 1985, 1986a; Sandholt, 1987] and geomagnetic perturbations [Lanzerotti et al.. 1986] have all been interpreted in terms of FTEs. Simultaneous direct magnetopause and ground-based observations of the phenomenon have not yet been documented, although inferences have been made by Goertz et al. and Lockwood et al. (submitted manuscript, 1988). The search for ground magnetic signatures [cf. McHenry and Clauer, 1987] has been particularly embarrassing, in part due to difficulties in separating effects of solar wind dynamic pressure pulses and FTE signatures [cf. Friis-Christensen et al., 1988; Farrugia et al., 1989], in part due to the small spatial (in latitude) and temporal scales of the central Hall current filament, associated with the discrete auroral precipitation and the complex evolution and structure of these events. The rather confusing situation resulting from such problems has, in view of the high occurrence rate of the magnetopause phenomenon, led to a widespread scepticism concerning the existence of FTE signatures in ground-based data. We note that such signatures must exist; however, only when the evolution, motion and conductivity distribution and variation during the events are understood, can they be identified with certainty.

The observations reported here and by Lockwood et al. [1989] i.e., coordinated optical, ion drift and geomagnetic data, are considered to be strong evidence of transient reconnection at the dayside magnetopause, commonly referred to as FTEs. Furthermore, the observed relationship between the optical signature, called dayside auroral breakup events, and the ion drift observations is found to be consistent with a convecting twinvortex flow/current pattern in the ionosphere, similar to that proposed by southwood [1985, 1987]. The geomagnetic signatures are also in accord with this interpretation.

A significant feature of the reported events is their initial sunward motion as 
they travel westward towards noon around the afternoon sector. This is readily explained in terms of an FTE signature by magnetic tension and the prevailling positive By component of the IMF. However, an alternative possibility is that a dynamic pressure change, aligned with the IMF vector (in this case in garden hose orientation as $B_{x}$ is negative), impinges on the afternoon sector magnetopause, generating boundary disturbances which propagate both east (toward the tail) and west (toward noon). It has been predicted theoretically that these can generate field-aligned currents and hence ionospheric flow signatures only if there is a density gradient across the low latitude boundary layer [Elphic, 1988; Southwood and Rivelson, 1989; Lee, 1989]. Recently, Farrugia et al. [1989] and Sibeck et al. [1989b] have provided experimental evidence for such ionospheric effects. This mechanism, like the Southwood FTE model, is expected to give rise to vortical flow patterns in the ionosphere [Elphic, 1988] and hence also offers an explanation of the twin-vortical flow pattern deduced from the radar and magnetometer data. However, as pointed out by Friis-Christensen et al. [1988], there is an important difference between these travelling vortices (modelled by Elphic [1988] in terms of dynamic pressure changes) and the southwood FTE model, in that the flow at the event centre cannot be the same as the motion of the event itself: the former will have a considerable component orthogonal to the boundary, while the event propagates largely along the boundary. The FTE signature, however, must have a velocity within the newly opened flux tube (averaged to remove the effects of twisting within the tube) which is identical to the event velocity. In the events described here the plasma flow velocity at the event centre (observed by EISCAT and the magnetometers) is always the same, to within experimental error, as the velocity of the event as a whole (determined from the T.V. images as well as the radar and magnetometer datal. This argues strongly in favour of interpretation in terms of the FTE model. However, the detailed field-aligned current configuration during the events is not known at present. Different configurations occur, associated with different IMF orientations. The configuration shown in Figure 7 of this paper is one possibility. Related to this, we note that the details of the E field structure associated with the discrete auroral forms will be a major objective during forthcoming campaigns, based on observations with upgraded radar technique.

Using the southwood FTE model interpretation, magnetic flux transfer rates [cf. Lockwood et al.. 1989] and associated induced electric potentials have been derived from the optical and ion drift data.
The 3-10 min period of the optical signature during the individual events appears to mark the time of momentum transfer to the cusp/cleft ionosphere. The optical observations, i.e., spectral composition and spatial structure, indicate the onset of field-aligned potential drops - $1 \mathrm{kV}$ between the magnetopause and the ionosphere during the events.

The present results may indicate that, in general, the ionospheric signature of the transient magnetopause reconnection process is most easily identified in the optical data, due to the significant emission intensities relative to the background cusp/cleft emission, the specific motion pattern, the temporal scale and the good temporal and spatial resolution of the optical instruments. The present events would hardly be identified from the magnetometer data alone, due to the small amplitudes in comparison with the background disturbance level in most cases, and the unsatisfactory station network. A dense ( $100 \mathrm{~km}$ ) network of stations is necessary in order to analyze the magnetic signatures properly, as pointed out by McHenry and Clauer [1987].

The most characteristic features of the interplanetary magnetic field during the 2-hour period (1230-1430 MLT) series of events observed on January 12, 1988, are the large By component, the stable amplitude and the changing orientation (IMP 8) during the few minutes preceding some of the more pronounced events. $B_{2}$ changed from large negative values (09000930 UT) to fluctuations around zero later in the period. During the first part of the interval the recurrence period is about $7 \mathrm{~min}$, and this may indicate some role during the period of consistently southward IMF, and of the IMF By component in triggering the magnetopause instability leading to topological connection of interplanetary and geomagnetic field lines [cf. Galeev et al., 1986 and references therein]. Other external influences on the magnetopause reconnection process, such as solar wind dynamic pressure variations, seem to be involved at times, but not always. In the absence of external modulations of the recurrence rate, we sipect events to regularly repeat due to an internal magnetospheric period of 8 min in any case. The 0930-1100 UT period shows that events can be triggered individually with longer recurrence times (here 20 min) by brief southward excursions of the IMF.

Appendix: Relationship Between the Optical and Geomagnetic Signatures

Auroral intensities derived from photometer recording along the magnetic meridian are used to derive the characteristic energy and the energy flux of the precipitating electrons, assuming a Maxwellian energy distribution [cf. Rees and Luckey, 1974; Rees and Roble, 1986]. 
This technique requires a stable aurora in the magnetic zenith. In such cases ionospheric conductances can be estimated from the optical spectral information. In the first step we derive the electron energy flux (E) and the characteristic energy $\left(\alpha=E_{\text {ave }} / 2\right)$ of the electron energy distribution function. The following formulas from Rees and Roble [1986] are used:

$$
\begin{gathered}
4 \pi I(630.0 \mathrm{~nm})[R]=420 \alpha^{-0.9} \epsilon\left(\operatorname{ergs~cm}^{-2} \mathrm{~s}^{-1}\right) \\
4 \pi I(427.8 \mathrm{~nm})[R]=213 \alpha^{0.0735} \epsilon\left(\mathrm{ergs} \mathrm{cm}^{-2} \mathrm{~s}^{-1}\right)( \\
\frac{4 \pi I(630.0 \mathrm{~nm})}{4 \pi I(427.8 \mathrm{~nm})}=2.00 \alpha^{-1}
\end{gathered}
$$

where $\alpha$ is given in keV. Relations (A1a)(A1C) apply to the range $0.1<\alpha<2.0$. When using $(A 1 B)-(A 1 C)$ in deriving electron precipitation parameters related to the dayside aurora one must, however, take into account the possible contribution to the $427.8 \mathrm{~nm}$ emission from resonance scattered sunlight. In the present work we checked the possible contamination from scattered sunlight by calculating the electron spectral parameter $a$ using the red to green line ratio and comparing with (AIC) [Rees and Luckey, 1974].

The height-integrated conductivities $\Sigma_{P}$ and $\Sigma_{\mathrm{H}}$ are then derived by the following formulas from Robinson et al. [1987]:

$$
\begin{gathered}
\Sigma_{P}(\text { mhos })=\frac{40 E_{\text {ave }}(k e V)}{16+E_{\text {ave }}^{2}} \epsilon^{\frac{1}{2}}\left(\text { ergs cm }{ }^{-2} s^{-1}\right) \\
\Sigma_{H}(m h o s)=0.45 E_{\text {ave }}^{0.85} \Sigma_{P}(\text { mhos })
\end{gathered}
$$

Assuming a belt current with infinite length and finite width in the ionosphere and that the ground magnetic field perturbation is due to the Hall component of the ionospheric currents (equivalent to an assumption that the conductivity heterogeneity is not significant, or the current is infinitely long; [cf. Fukushima, 1969; Friis-Christensen, 1986]), the horizontal ( $\mathrm{BH}_{\mathrm{B}}$ ) and vertical ( $\mathrm{B}_{2}$ ) components of the deflection vector on the ground can be expressed as (Biot-Savart's law)

$$
\begin{aligned}
& \Delta B_{H} \approx \frac{\mu_{0} g_{1}}{2 \pi} \int_{x_{1}}^{x_{2}} \Sigma_{H} E_{N} \frac{h}{h^{2}+x^{2}} d x \\
& \Delta B_{Z} \approx \frac{\mu_{0} g_{2}}{2 \pi} \int_{x_{1}}^{x_{2}} \Sigma_{H} E_{N} \frac{x}{h^{2}+x^{2}} d x
\end{aligned}
$$

where $h$ represents the current altitude, and the integration by $d x$ is carried out across the current belt.

For the ground reflection factors we use $g_{1}=g_{2}=1$ (a current sheet lying above a perfectly conducting Earth corresponds to $g_{1}=2, g_{2}=0$. . Assuming $a$ uniform current belt, (A3a) and (A3b) can be written as follows:
$\Delta B_{H}(n T) \approx 200\left(\tan ^{-1} \frac{x_{2}}{h}-\tan ^{-1} \frac{x_{1}}{h}\right) \Sigma_{H}(m h o s) E_{N}\left(V m^{-1}\right)(\mathrm{A} 4 \mathrm{a})$

$$
\Delta B_{Z}(n T) \approx-200 \ln \frac{h^{2}+x_{2}^{2}}{h^{2}+x_{1}^{2}} \Sigma_{H}(m h o s) E_{N}\left(V m^{-1}\right)
$$

The above indicated procedure will then be applied to the 0920-0925 UT auroral event. The westward moving auroral structure (Figures $3 a$ and $3 b$ ) reached the photometer scanning plane around 0921:35 UT and caused the photometer intensities at 0921:50 UT as given in table 1. The corresponding electron parameters ( $\alpha$ and $E$ ) and the resulting ionospheric conductances are also noted in the table. During the next minute the photometer intensities were slowly decreasing and the intensity peaks moving toward the magnetic zenith $i^{-}-10^{\circ}$ south of zenith). In the calculations here we have not corrected for the effect of the auroras being located slightly off the magnetic zenith. From table 1 we notice a decrease of $\sum$ from 3.0 to 0.4 mho within the 70-s interval considered.

In the next step we insert typical values for Hall conductance, northward electric field ( $E_{N}$ ) and latitudinal extent of the resulting Hall current belt for the 0922-0923 UT interval. For $\sum$ H we use 1 mho as an average value. The radar measured $\mathrm{E}_{\mathrm{N}}=150 \mathrm{mV} / \mathrm{m}\left(3 \mathrm{~km} \mathrm{~s} \mathrm{~s}^{-1}\right.$ westward drift) in gates 6,7 , and 8 (cf. Figures 1 and 2) at 0923:10 UT. A decrease of $E_{N}$

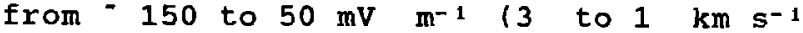
westward ion flow) was observed from gates 6 to 4. Thus, a Hall current belt characterized by the average values $\sum \mathrm{B}=$ 1 mho, $\mathbf{E}_{\mathbf{N}}=150 \mathrm{mV} \mathrm{m}^{-1}$ and latitudinal extent of $200 \mathrm{~km}$ (from $250 \mathrm{~km}$ to $50 \mathrm{~km}$ south of $\mathrm{Ny}$ Alesund) is derived from the optical and radar measurements. Inserting these values in (A4a) and (A4b) we obtain $\Delta \mathrm{Br}_{\mathrm{H}}=20 \mathrm{nT}$ and $\Delta \mathrm{B}_{2}=-50 \mathrm{nT}$. The observed peak values at this time are $\Delta \mathrm{H}=30$ $\mathrm{nT}$ and $\Delta \mathbf{Z}=-45 \mathrm{nT}, \mathrm{i} . \mathrm{e}$. deviation from the background perturbation (cf. Figure $5 b)$. The negative $D$ component is consistent with a tilted current/flow pattern with respect to geographic east-west, as indicated schematically in Figure $7 \mathrm{~b}$.

The relationship between the optical and magnetic events is illustrated by the additional case reported in Figures A1 and $\mathrm{A} 2$. Figure $\mathrm{A1}$ shows scanning photometer traces for a 25-min period near local noon $\left(^{-} 0830\right.$ UT) on December. 10, 1983 , elucidating a characteristic behavior of the optical events. These photometer records were obtained at Longyearbyen, $115 \mathrm{~km}$ to the south of Ny Alesund (nearly along the magnetic meridian). The zenith angle position corresponding to $630.0-\mathrm{nm}$ emission at $250 \mathrm{~km}$ altitude above $\mathrm{Ny}$ Alesund (magnetometer site, cf. Figure A2) is marked on the horizontal axis of the photometer stack plot. Notice the initial equatorward excursion of discrete emission maximizing at 0818 UT, well equatorward of the preexisting cusp arc (close to the latitude of Hornsund), 


\section{SVALBARD DEC.10,1983 \\ CUSP AURORA}

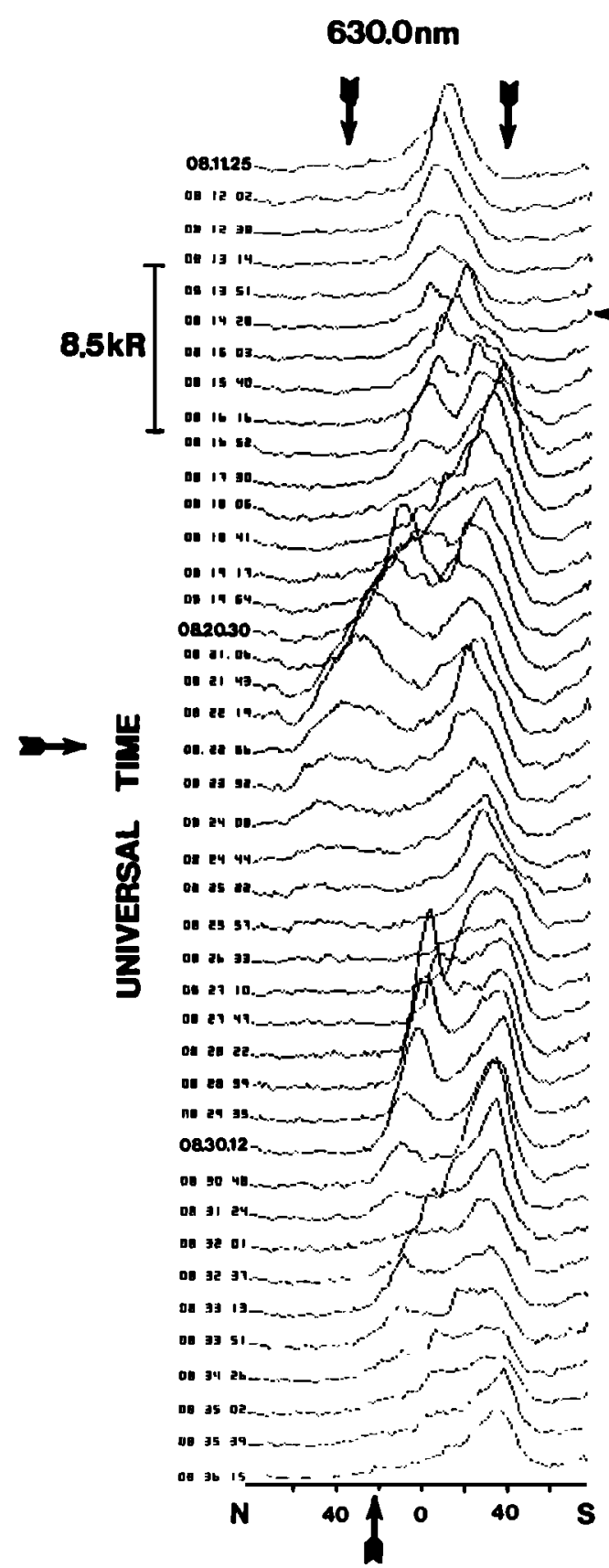

ZENITH ANGLE 427.8nm

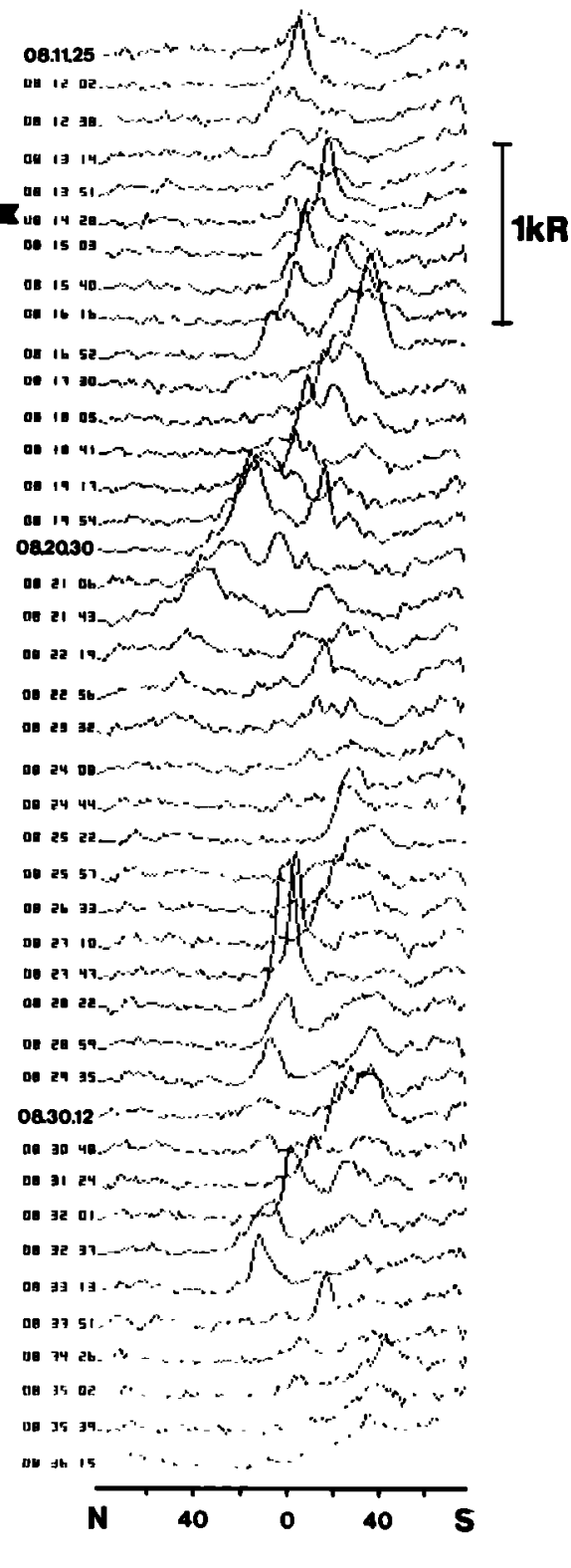

ZENITH ANGLE

Fig. A1. North-south meridian-scanning photometer profiles of the red oxygen line at $630.0 \mathrm{~nm}$ (left panel) and the blue band $\left(\mathrm{N}_{2}\right.$ ) at $427.8 \mathrm{~nm}$ (right panel) obtained from Longyearbyen. Svalbard. Arrows in the left panel mark the spans in zenith angle and time of a transient auroral event. The zenith angle position of $250-\mathrm{km}$ altitude aurora above $\mathrm{Ny}$ Alesund is indicated on the horizontal axis in the left panel [from Sandholt et al., 1986a].

followed by a poleward motion and subsequent decay around $0823 \mathrm{UT}$, close to the latitude of Ny Alesund. The average velocity of poleward motion during this
5 -min interval was $1.1 \mathrm{~km} \mathrm{~s} \mathrm{~s}^{-1}$. The associated magnetic deflection at $\mathrm{Ny}$ Alesund maximized at $0818 \mathrm{UT}$, with $\Delta \mathrm{H} \simeq 50 \mathrm{nT}$ and negative $\Delta \mathrm{D}$ and $\Delta \mathrm{Z}$, consistent with an 


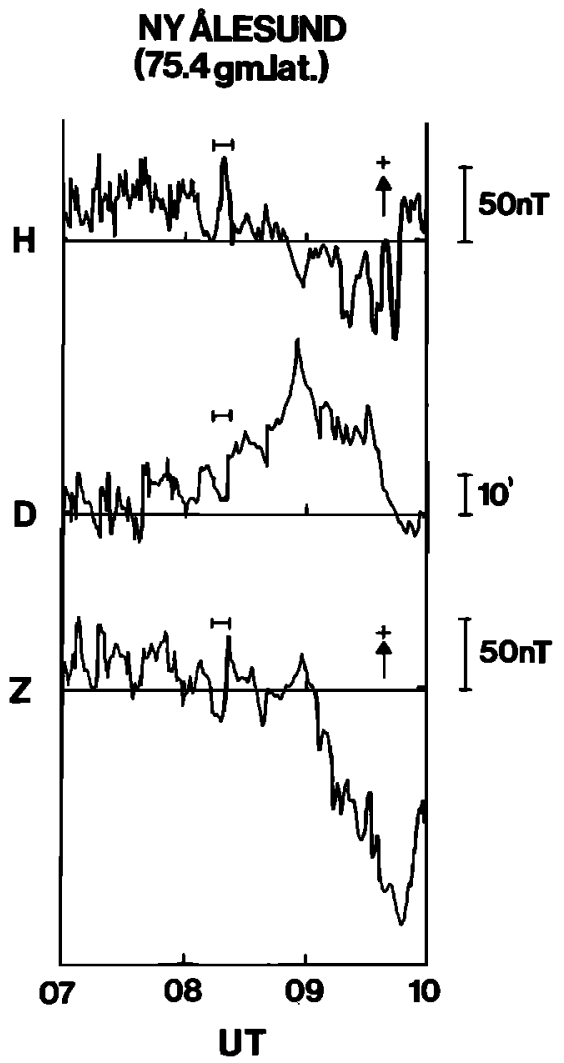

Fig. A2 . H, D, and $\mathrm{Z}$ component magnetograms from Ny Alesund for December 10 , 1983. The duration of the photometer event shown in Figure $A 1$ is marked by horizontal bars in each panel.

eastward Hall current filament located to the south of the magnetometer station.

At this time the Hornsund magnetograms show a similar $\mathrm{H}$ component peak as in $\mathrm{Ny}$ Alesund, but with $\Delta z$ nearly zero, indicating a Hall current filament overhead, associated with the discrete aurora. A smaller initial negative $H$ deflection maximized (in amplitude) at Hornsund at 0814 UT (cf. also the Ny Alesund trace in Figure A2), indicative of a poleward moving vortex pattern during the event.

The equatorward excursion of the discrete emission relative to the preexisting cusp arc equatorward boundary in the early phase of the event (0814-0818 UT) is in accordance with FTE model predictions of an initial equatorward bulge on the polar cap boundary [cf. Cowley, 1986, Figure 13a].

An alternative interpretation is that the initial phase with equatorward auroral expansion is produced by a solar wind dynamic pressure pulse, although no indication is seen in the ISEE 2 magnetosheath magnetic field data. ISEE 2 observations of the external magnetic field, within the magnetosheath, show the following values during the time of the observations reported above: $B_{2}=-30$ $\mathrm{nT}, \mathrm{By}=21 \mathrm{nT}, \mathrm{Bx} \approx 0 \mathrm{nT}, \mathrm{BT}_{\mathrm{T}}=39 \mathrm{nT}$ [cf. also sandholt et al., 1986a, Figure 1a].
Acknowledgments. The authors are grateful to R. Lepping, Goddard Space Flight Center, for provision of the IMP 8 data and to A. Brekke/B. Holmeslett, University of Troms $\varnothing$, and $W$. Krainsky, Polish Academy of Science, Warzsaw, for magnetometer data used in this paper. We also thank the Director and staff of EISCAT for their assistance: EISCAT is supported by the research councils of France (CNRS), West Germany (MPG), Norway (NAVF), Sweden (NFR), Finland (SA), and the UK (SERC). Thanks are due to the Norwegian Polar Research Institute, NAVF and Kyoikusha Ltd, for the support to the optical observation campaign at Ny Alesund. This study was sponsored by NATO collaborative research grant $85 / 0521$.

The Editor thanks D. Andre and C.-I. Meng for their assistance in evaluating this paper.

\section{References}

Axford, W. I., Magnetic field reconnection, in Magnetic Reconnection in Space and Laboratory Plasmas, Geophys. Monogr. Ser., vol. 30, edited by E. W. Hones, Jr., pp. 1-8, AGU, Washington, D. C., 1984 .

Baumjohann, W., and G. Paschmann, Solar wind-magnetosphere coupling: Processes and observations, Phys. Scr., $\underline{T} 18$, $61-72,1987$.

Bromage, B. J. I., Errors in velocities determined from EISCAT data, J. Atmos. Terr. Phys., 46, 577-591, 1984 .

Burch, J. L.. Quasi-neutrality in the polar cusp, Geophys. Res. Lett., 12, 469-472, 1985 .

Clauer, C. R., P. M. Banks, A. Q. Smith, T. S. Jörgensen, E. Friis-Christensen, S. Vennerström, V. B. Wickwar, J. D. Kelly, and J. D. Doupnik, Observations of interplanetary magnetic field and of ionospheric plasma convection in the vicinity of the dayside polar cleft, Geophys. Res. Lett., 11, 891894,1984 .

Cogger, L. L., J. S. Murphree, S. Ismail, and $C$. D. Anger, Characteristics of dayside 5577A and $3914 \mathrm{~A}$ aurora, Geophys. Res. Lett., 4, 413-416, 1977 .

Cowley, S. W. H., The causes of convection in the Earth's magnetosphere: A review of developments during the IMS, Rev. Geophys., 20, 531-565，1982.

Cowley, S. W. H., Solar wind control of magnetospheric convection, Achievements of the International Magnetospheric Study IMS, Eur. Space Agency Spec. Publ, ESA SP-217, 483-494, 1984.

Cowley, S. W. H., The impact of recent observations on theoretical understanding of the solar wind-magnetosphere interactions, J. Geomagn. Geoelectr., 38, 1223-1256, 1986 .

Blphic, R. C., Multipoint observations of the magnetopause: Results from ISEE and AMPTE, Adv. Space Res., 8, (9)223(9) 238,1988 . 
Erlandson, R. E., L. J. Zanetti, T. A. Potemra, and P. F. Bythrow, IMF By dependence of region 1 Birkeland currents near noon, J. Geophys. Res.' 93. 9804-9814, 1988 .

Etemadi, A., S. W. H. Cowley, M. Lockwood, B. J. I. Bromage, D. M. Willis, and $H$. Lühr, The dependence of highlatitude dayside ionospheric flows on the north-south component of the IMF: A high time resolution correlation analysis using EISCAT "POLAR" and AMPTE UKS and IRM data, Planet. Space Sci., 36, 471-498, 1988 .

Etemadi, A., S. W. H. Cowley, and $M$. Lockwood, The effect of rapid changes in ionospheric flow on velocity vectors deduced from radar beamswinging experiments, J. Atmos. Terr. Phys., 51, 125-138, 1989 .

Farrugia, C. J., M. P. Freeman, S. W. H. Cowley, D. J. Southwood, M. Lockwood, and $A$. Etemadi, Pressure-driven magnetopause motions and attendant response on the ground, Planet. Space Sci., in press, 1989.

Friis-Christensen, E., Solar wind control of the polar cusp, in solar WindMagnetosphere Coupling, edited by $Y$. Kamide and J. A. Slavin, Terra, Tokyo, 1986 .

Friis-Christensen, E., M. A. McHenry, C. $R$. Clauer, and $S$. Vennerström, Ionospheric traveling convection vortices observed near the polar cleft: $A$ triggered response to sudden changes in the solar wind, Geophys. Res. Lett., 15, 253-256, 1988 .

Fukushima, N., Equivalence in ground geomagnetic effect of Chapman-Vestine and Birkeland-Alfvén electric current systems for polar magnetic storms, Rep. Ionos. Space Res. Jpn., 23, 219227,1969 .

Galeev, A. A., M. M. Kuznetsova, and L. M. Zeleny, Magnetopause stability threshold for patchy reconnection, Space Sci. Rev., 44, 1-41, 1986.

Glassmeier, R.-H., M. Hoenish, and $J$. Untiedt, Ground-based and satellite observations of traveling magnetospheric convection twin vortices, $J$. Geophys. Res.' 94, 2520-2528, 1989.

Goertz, C. K., E. Nielsen, A. Korth, K.H. Glassmeier, C. Haldoupis, P. Hoeg, and D. Hayward, Observations of a possible ground signature of flux transfer events, J. Geophys. Res., 90, 4069-4078, 1985.

Kan, J. R., A theory of patchy and intermittent reconnections for magnetospheric flux transfer events, J. Geophys. Res., 93, 5613-5623, 1988 .

Kokubun, S., T. Yamamoto, K. Hayashi, T. Oguti, and A. Egeland, Impulsive Pi bursts associated with poleward moving auroras near the polar cusp, J. Geomagn. Geoelectr., 40, 537-551, 1988 .

Lanzerotti, L. J., L. C. Lee, C. G. Maclennan, A. Wolf, and L. V. Medford, Possible evidence of flux transfer events in the polar ionosphere, Geophys. Res. Lett., 13, 1089-1092, 1986 .

Lee, L. C., Generation of field-aligned currents by pressure pulses in the magnetosphere, Geophys. Res. Lett., in press, 1989.

Lee, L. C.. and Z. F. Fu, A theory of magnetic flux transfer at the magnetopause, Geophys. Res. Lett., 12, 105108,1985 .

Lee, L. C., Y. Shi, and L. J. Lanzerotti, A mechanism for the generation of cusp region hydromagnetic waves, J. Geophys. Res., 93, 7578-7585, 1988 .

Lemaire, J., Impulsive penetration of filamentary plasma elements into the magnetospheres of the Earth and Jupiter, Planet. Space Sci., 25, 887-890, 1977 .

Lockwood, M., and S. W. H. Cowley, Observations at the magnetopause and in the auroral ionosphere of momentum transfer from the solar wind, Adv. Space Res., 8, (9) 281-(9) 299, 1988 .

Lockwood, M., A. P. Van Eyken, B. J. I. Bromage, D. M. Willis, and S. W. H. Cowley, Eastward propagation of a plasma convection enhancement following a southward turning of the interplanetary magnetic field, Geophys. Res. Lett., 13, 72-75, 1986 .

Lockwood, M., M. F. Smith, C. J. Farrugia, and G. L. Siscoe, Ionospheric ion upwelling in the wake of flux transfer events at the dayside magnetopause, J. Geophys. Res., 93, 5641-5654, 1988.

Lockwood, M.. P. E. Sandholt, and S.W. H. Cowley, Dayside auroral activity and momentum transfer from the solar wind, Geophys. Res. Lett., 16, 33-36, 1989 .

Lundin, R.. Solar wind energy transfer regions inside the dayside magnetopause, II, Evidence for an MHD generator process, Planet. Space sci., 32 , 757-770, 1984.

Lundin, R.. Processes in the magnetospheric boundary layer, Phys. Scr., T18, $85-102,1987$.

Marklund, G., Auroral arc classification scheme based on the observed arcassociated electric field pattern, Planet. Space Sci., 32, 193-211, 1984.

McHenry, M. A., and C. R. Clauer, Modeled ground magnetic signatures of flux transfer events, J. Geophys. Res., 92, 11231-11240, 1987 .

McHenry, M. A., C. R. Clauer, E. FriisChristensen, and J. D. Kelly, Observations of ionospheric convection vortices: Signatures of momentum transfer, Adv. Space Res., \&, (9) 315-(9) 320, 1988 .

Meng, C.-I., and R. Lundin, Auroral morphology of the midday oval, J. Geophys. Res.' 91, 1572-1584, 1986.

Moses, J. J., G. L. Siscoe, R. A. Heelis, and $J$. D. Winningham, A model for multiple throat structures in the polar cap flow entry region, J. Geophys. Res., 93, 9785-9790, 1988 . 
Mozer, F. S., Electric field evidence on the viscous interaction at the magnetopause, Geophys. Res. Lett., 11, $135-138,1984$.

Newell, P. T., and C.-I. Meng, Cusp width and $\mathrm{Bz}_{2}$ : Observations and a conceptual model, J. Geophys. Res., 92, 1367313678,1987 .

Oguti, T., T. Yamamoto, K. Hayashi, S. Kokubun, A. Egeland, and J. A. Holtet, Dayside auroral activities and related magnetic impulses in the polar cusp region, J. Geomagn. Geoelectr., 40. $387-408,1988$.

Paschmann, G., I. Papamastorakis, W. Baumjohann, N. Sckopke, C. W. Carlson, B. U. O. Sonnerup, and H. Luhr, The magnetopause for large magnetic shear: AMPTE/IRM observations, J. Geophys. Res.. 91, 11099-11115, 1986.

Potemra, T. A., H. Lühr, L. J. Zanetti, K. Takahashi, R. E. Erlandson, G. T. Marklund, L. P. Block, L. G. Blomberg, and R. P. Lepping, Multi-satelitte and ground-based observations of transient ULF waves, J. Geophys. Res., 94, 2543$2554,1989$.

Rees, M. H., and D. Luckey, Auroral electron energy derived from ratios of spectroscopic emissions, 1, Model computations, J. Geophys. Res., 79, $5181-5186,1974$.

Rees, M. H., and R. G. Roble, Excitation of $O$ (1D) atoms in aurora and emission of the [OI] 6300A line, Can. J. Phys., 64, 1608-1613, 1986 .

Reiff, P. H., T. W. Hill, and J. L. Burch, Solar wind plasma injection at the dayside magnetospheric cusp, J. Geophys. Res.. 82, 479-491, 1977.

Rijnbeek, R. P., S. W. H. Cowley, D. J. Southwood, and C. T. Russell, A survey of dayside flux transfer events observed by ISEE 1 and 2 magnetometers. $\mathrm{J}$. Geophys. Res., 89, 786-800, 1984

Rishbeth, H., P. R. Smith, S. W. H. Cowley, D. M. Willis, A. P. van Eyken, B. J. I. Bromage, and S. R. Crothers, Ionospheric response to changes in the interplanetary magnetic field observed by EISCAT and AMPTE-UKS, Nature, $318,451-452,1985$

Robinson, R. M., R. R. Vondrak, K. Miller, T. Dabbs, and D. Hardy, on the calculation of conductances from the flux and energy of precipitating electrons, J. Geophys. Res., 92, 2565$2569,1987$.

Russe11, C. T., and R. C. Elphic, ISEE observations of flux trans-fer events at the dayside magnetopause, Geophys. Res. Lett., $6,33-36,1979$.

Sandholt, P. E., Interplanetary and geophysical effects of a coronal transient, Ann. Geophys., Ser. A, 5, 219230,1987 .

Sandholt, P. E., IMF control of the polar cusp and cleft auroras, Adv. Space Res., 8, (9) 21-(9)34, 1988 .

Sandholt, P. E., and A. Egeland, Auroral and magnetic variations in the polar cusp and cleft - signatures of magnetopause boundary layer dynamics, Astrophys. Space Sci., 144, 171-199, 1988 .

Sandholt, P. E., A. Egeland, J. A. Holtet, B. Lybekk, $K$. Svenes, and $S$. Asheim, Large- and small-scale dynamics of the polar cusp, J. Geophys. Res., 90, 4407-4414, 1985.

Sandholt, P. E., C. S. Deehr, A. Egeland, B. Lybekk, R. Viereck, and G. J. Romick, Signatures in the dayside aurora of plasma transfer from the magnetosheath, J. Geophys. Res., 91, 10063-10079, 1986a.

Sandholt, P. E., A. Egeland, and B. Lybekk, on the spatial rela-tionship between auroral emissions and magnetic signatures of plasma convection in the midday polar cusp and cap ionospheres during negative and positive IMF $\mathrm{B}_{2}$ : $\mathrm{A}$ case study, J. Geophys. Res., 91, 12108-12112, $1986 \mathrm{~b}$.

Sandholt, P. E., B. Lybekk, A. Egeland, $R$. Nakamura, and $T$. Oguti, Midday auroral breakup, J. Geomagn. Geoelectr. $41,371-387$, 1989a.

Sandholt, P. E., B. Jacobsen, B. Lybekk, A. Egeland, P. F. Bythrow, and D. A. Hardy, Electrodynamics of the polar cusp ionosphere: A case study, J. Geophys. Res.' 94, 6713-6722, $1989 \mathrm{~b}$.

Saunders, M. A., Origin of the cusp Birkeland currents, Geophys. Res. Lett., 16, 151-154, 1989 .

Saunders, M. A., C. T. Russell, and N. Sckopke, Flux transfer events: Scale size and interior structure, Geophys. Res. Lett., 11, 131-134, 1984.

Schindler, $K_{.}$, on the role of irregularities in plasma entry into the magnetosphere, J. Geophys. Res., 84, 7257$7266,1979$.

Scholer, M., Magnetic flux transfer at the magnetopause based on single $x$ line bursty reconnection, Geophys. Res. Lett., 15, 291-294, 1988 .

Sibeck, D. G., W. Baumjohann, R. C. Elphic, D. H. Fairfield, J. F. Fennell, W. B. Gail, L. J. Lanzerotti, R. E. Lopez, H. Lühr, A. T. Y. Lui, C. G. Maclennan, R. W. McEntire, T. A. Potemra, T. J. Rosenberg, and $\mathrm{K}$. Takahashi, The magnetospheric response to 8-minute-period strong-amplitude upstream pressure variations, $J$. Geophys. Res., 94, 2505-2519, 1989a.

Sibeck, D. G., W. Baumjohann, and R. E. Lopez, Solar wind dynamic pressure variations and transient magnetospheric signatures, Geophys. Res. Lett., $16,13-16,1989 \mathrm{~b}$.

Sonnerup, B. U. O., G. Paschmann, I. Papamastorakes, N. Sckopke, G. Haerendel, S. J. Bame, J. R. Asbridge, J. T. Gosling, and C. T. Russell, Evidence for magnetic field reconnection at the Earth's magnetopause, J. Geophys. Res., 86, 10049-10067, 1981 .

Southwood, D. J., Theoretical aspects of ionosphere-magnetosphere-solar wind 
coupling, Adv. Space Res., 5, 7-14, 1985.

southwood, D. J., The ionospheric signature of flux transfer events, $\mathrm{J}$. Geophys. Res.' 92, 3207-3213, 1987.

Southwood, D. J., Magnetopause coupling processes and ionospheric responses: a theoretical perspective, Philos. Trans. R. Soc. London, Ser. $A, \underline{328}$, 79, 1989 .

Southwood, D. J., and M. G. Kivelson, The magnetohydrodynamic response of the magnetospheric cavity to changes in solar wind pressure, J. Geophys. Res.. in press, 1989.

Southwood, D. J., C. J. Farrugia, and M. A. Saunders, What are flux transfer events?. Planet. Space Sci., 36, 503508,1988 .

Stern, D. P.. The origins of Birkeland currents, Rev. Geophys., 21, 125-138, 1983.

Todd, H., B. J. I. Bromage, S. W. H. Cowley, M. Lockwood, A. P. van Eyken, and $D$. M. Hillis, EISCAT observations of bursts of rapid flow in the high latitude dayside ionosphere, Geophys. Res. Lett., 13, 909-912, 1986.

Todd, H., S. W. H. Cowley, A. Etemadi, B. J. I. Bromage, M. Lockwood, D. M. Willis, and $H$. Lühr, Flow in the highlatitude ionosphere: Measurements at 15-second resolution mode using the EISCAT "POLAR" experiment, J. Atmos. Terr. Phys., 50, 423-446, 1988a.

Todd, H., S. W. H. Cowley, A. Etemadi, M. Lockwood, D. M. Willis, and H. Lūhr, Response of flow in the high latitude ionosphere to sudden changes in the north-south component of the IMF, Planet. Space. Sci., 36, 1415-1428, $1988 \mathrm{~b}$. van Eyken, A. P., H. Rishbeth, D. M. Willis, and S. W. H. Cowley, Initial observations of plasma convection at invariant latitudes $70-77^{\circ}$, J. Atmos. Terr. Phys., 46, 635-641, 1984 .

Willis, D. M., M. Lockwood, S. W. H. Cowley, A. P. van Eyken, B. J. I. Bromage, H. Rishbeth, P. R. Smith, and S. R. Crothers, A survey of simultaneous observations of the high-latitude ionosphere and interplanetary magnetic field with EISCAT and AMPTE-UKS, J. Atmos. Terr. Phys., 48, 987-1008, 1986 .

Wright, A. W. The evolution of an isolated reconnected flux tube, planet. Space Sci., 3ㄷ․ 813-819, 1987.

Wygant, J.R., R. B. Torbert, and F. S. Mozer, Comparison of s3-3 polar cap potential drops with the interplanetary magnetic field and models of magnetopause reconnection, J. Geophys. Res., 88, 5727-5735, 1983.

S. W. H. Cowley, Blackett Laboratory, Imperial College, London SW7 2BZ, England.

A. Egeland, B. Lybekk, and P. E. Sandholt, Department of Physics, University of Oslo, P. O. Box 1048, Blindern. 0316 Oslo 3, Norway.

K. S. C. Freeman, M. Lockwood, and D. M. Willis, Rutherford Appleton Laboratory, Chilton, Didcot OX11 OQX, England.

T. Oguti, University of Tokyo, Geophysics Research Laboratory, Tokyo 113, Japan.

(Received February 13, 1989; revised April 24, 1989; accepted April 24, 1989.) 